\section{A. ARS BILDUMA ISSN 1989-9262 UPV/EHU Press} ARSBILDUMA (CC BY-NC-ND 4.0)

https://doi.org/10.1387/ars-bilduma.20554 BIBLID [(2020), 10; 69-89]

Recibido: 30/01/2019 Aceptado: 28/11/2019

\section{JAVIER ITÚRBIDE DÍAZ}

UNED Pamplona

Calle del Sadar, S/N

31006 Pamplona (Navarra)

javier.iturbide@yahoo.es

https://orcid.org/0000-0001-6456-7215

\title{
EL LIBER MAGNIFICARUM DEL POLIFONISTA MIGUEL NAVARRO IMPRESO POR CARLOS LABAYEN EN 1614
}

\author{
THE LIBER MAGNIFICARUM FROM THE POLYPHONIST MIGUEL NAVARRO \\ PRINTED BY CARLOS LABAYEN IN 1614
}

\section{LE LIBER MAGNIFICARUM DU POLYPHONISTE MIGUEL NAVARRO IMPRIMÉ PAR CARLOS LABAYEN EN 1614}

RESUMEN

La impresión de un libro con música polifónica en un taller de Pamplona a comienzos del siglo XVII, como sucediera en otros europeos de similar rango, constituye un hecho excepcional: hacía más de un siglo que en la capital navarra no se había impreso una obra con notación musical y transcurrieron más de dos siglos para que saliera a la luz otra similar. El presente artículo analiza las circunstancias editoriales, técnicas y comerciales del Liber Magnificarum.

\section{PALABRAS CLAVE}

Libros de música; Pamplona; Zaragoza; siglo XVII; polifonía; Miguel Navarro; Carlos Labayen.

\section{ABSTRACT}

The book printed with polyphonic music in a workshop in Pamplona at the beginning of the 17th century, in the meantime other similar europeans workshops of equivalent expertise, constituted an exceptional event. Testimony of this relevant event, is that in Navarra some form of musical was dated from over half a century ago, however over two centuries had to pass fo a similar printed work to come to fruition. The present article analyses the editorial, technical and commercial background surrounding the Liber Magnificarum.

\section{KEYWORDS}

Music books; Pamplona; Zaragoza; 17th Century; polyphony; Miguel Navarro; Carlos Labayen.
RÉSUMÉ

La publication d'un livre avec musique polyphonique dans une imprimerie de Pamplona au début du XVIIème siécle, de la meme maniére que si elle se réalisait dans d'autres ateliers européèns de même niveau, représente un événement exceptionel. Depuis plus d'un siècle, dans la capitale de Navarra, aucun livre à notation musicale n’avait été imprimé et il faudra attendre plus de deux siècles pour qu'apparaisse une publication similaire. Le travail actuel analyse les circonstances éditoriales, techniques et commerciales de la publication du Libre Magnificarum.

\section{MOTS-CLÉS}

Livres de musique; Pamplona; Zaragoza; XVIIème siécle; polyphonie; Miguel Navarro; Carlos Labayen. 


\section{CARÁCTER INUSITADO DE LA IMPRESIÓN DE UN LIBRO DE MÚSICA EN LAS IMPRENTAS NAVARRAS DEL SIGLO XVII}

La aparición, en 1614, de una publicación musical del maestro de capilla de la catedral de Pamplona, Miguel Navarro, con el pie de imprenta del taller pamplonés de Carlos Labayen, es un hecho extraordinario; fundamentalmente, porque, a excepción de dos misales impresos, en 1500 y en torno a 1501 respectivamente, por Arnao Guillén de Brocar, y de la obra de Miguel Navarro aquí estudiada, en la imprenta navarra de los siglos XV, XVI, XVII, XVIII y de la primera mitad del XIX, periodo en el que ve la luz un millar largo de libros impresos, ninguno de ellos contiene notación musical ${ }^{1}$. Salvo excepciones como pueden ser la prestigiosa Typographia Regia de Madrid, bajo la dirección de Juan Flamenco Ioannem Flandrum-, o los talleres salmantinos de Francisco de Cea Tessa ${ }^{2}$ y de Artus Taberniel ${ }^{3}$, tal como destaca Gosálvez: "En España la actividad de la imprenta de música durante el siglo XVII fue muy reducida y, si en épocas anteriores el volumen de producción era ya notablemente pequeño, durante el reinado de los últimos tres Austrias llegó a ser mínimo"4.

Las dificultades para la edición de este tipo de obras estribaban fundamentalmente en la débil demanda, en la poderosa oferta extranjera — procedente mayoritariamente de Italia, Francia y Flandes- más competitiva que la nacional, y, con carácter más inmediato, en la escasez de componedores especializados en textos de música, además del elevado coste de los tipos móviles musicales. Por todo ello, la impresión en el taller pamplonés de Carlos Labayen a comienzos del siglo XVII del Liber Magnificarum llama poderosamente la atención porque en su imprenta se componían textos en castellano, latín y euskera, pero

1 ITÚRBIDE DÍAZ J. Los libros de un Reino: Historia de la edición en Navarra (1490-1841). Pamplona, Gobierno de Navarra, 2015, pp. 28-31. Arnao Guillén de Brocar, en 1500 sacó a la luz el Missale Tirasonensis y, hacia 1501, el Missale Pampilonensis con notación musical. En 1848 se publicó en la imprenta pamplonesa de José Imaz y Gadea el Nuevo método completo teórico-práctico de canto-llano y figurado, del sacerdote pamplonés Fermín Ruiz de Galarreta (1815-1882); el volumen tiene 160 páginas con abundantes piezas gregorianas impresas con tacos xilográficos abiertos por el propio autor.

2 DELGADO CASADO, J.: Diccionario de impresores españoles (Siglos XV-XVII). Madrid, Arco Libros, 1996, p.136.

3 FENLON, I. "Artus Taberniel: Music Printing and the Book Trade in Renaissance Salamanca", Early Music Printing and Publishing in the Iberian World, ed. I. Fenlon y T. Knighton. Kassel, Reichenberger, 2006, pp. 117-146

4 GOSÁLVEZ LARA, C.J.: La edición musical española hasta 1936. Guía para la datación de partituras. Madrid, Asociación Española de Documentación Musical, 1995, p. 29. difícilmente podrían hacer otro tanto con obras polifónicas como las de Miguel Navarro ${ }^{5}$ Además, estos trabajos requerían tipos especiales —claves, tiempos, espacios y notas y cada uno de ellos con su respectivo pautado- que por su rareza y diversidad, particularmente en las obras polifónicas, serían escasos, trabajosos para abrir y fundir y, consiguientemente, exigirían un alto precio. Por todo ello, es improbable que Carlos Labayen dispusiera en su taller pamplonés de tipos musicales y que contara con profesionales capaces de componer obras de música. Si así hubiera sido los hubiera aprovechado, él o sus sucesores, para sacar a la luz más ediciones de estas características. Por lo expuesto hasta aquí, sorprende encontrar un libro de música impreso en Pamplona en el taller de Carlos Labayen.

\section{EL LIBER MAGNIFICARUM DE MIGUEL NAVARRO}

Tan solo se conocen dos ejemplares: uno localizado en Zaragoza y el otro en Tarazona. $\mathrm{Al}$ primero de ellos le falta la portada y el segundo está completo, esta circunstancia y la existencia de algunas composiciones musicales comunes en ambos ejemplares, han llevado con frecuencia a considerarlos como pertenecientes a una misma edición, lo cual, como a continuación se va a exponer, no es exacto.

\subsection{Ejemplar de Zaragoza}

El Archivo de Música de las Catedrales de Zaragoza ${ }^{6}$ guarda un ejemplar del Liber Magnificarum al que le falta la portada, que ha sido arrancada y que debía de ser una hoja independiente, pues se conserva parte de la cartivana que la unía al primer pliego. En las cabeceras de los folios pares se lee que su autor es Miguel Navarro cuyas composiciones musicales ocupan la totalidad del volumen, que por el contenido y tamaño se trata de un libro de coro, con formato en folio mayor, que tiene 104 folios y mide 43 por $29 \mathrm{~cm}^{7}$.

5 ITÚRBIDE DÍAZ, J.: Los libros de un Reino: Historia de la edición en Navarra (1490-1841). Pamplona, Gobierno de Navarra, 2015, p. 232

6 Mi agradecimiento a Luis Antonio González (Archivo Musical de los Archivos de las Catedrales de Zaragoza) por las facilidades ofrecidas para la consulta de este ejemplar y sus precisiones sobre las características musicales.

7 SAGASETA ARÍZTEGUI, A.: Miguel Navarro (ca. 1563-1627). Opera Omnia. Pamplona, Capilla de Música de la Catedral de Pamplona, 2006, p. 21, nota 65. Posiblemente por una errata tipográfica, indica que tiene 404 folios, en lugar de 104 


\subsubsection{Colación}

[]$^{1}, \mathrm{~A}-\mathrm{L}^{8}, \mathrm{M}^{6}, \mathrm{~N}^{2}, \mathrm{O}-\mathrm{P}^{4}=(1+88+6+1+8)=104$ hojas o folios.

[1], 102 [i.e. 103] h.: principalmente notación musical; Fol. (43×29 cm).

Tiene erratas en cuanto a la fijación de las signaturas tipográficas, a saber: « $\mathrm{F}_{5}\left[\right.$ i.e. $\left.\mathrm{F}_{3}\right] », « \mathrm{H}_{5}$ [i.e. $\left.\mathrm{H}_{4}\right] », \ll \mathrm{O}_{3}-\mathrm{O}_{5}$ [i.e. $\left.\mathrm{O}_{2}-\mathrm{O}_{4}\right] »$.

En cuanto a las erratas de foliación: 4 [i.e. 3], 5 [i.e. 6], 7 [i.e. 8], 24 [i.e. 23], 73 [i.e. 74] que no lo recupera y se mantiene la errata hasta el final, de modo que la última hoja numerada indica 102 [i.e. 103]. La hoja 5 está sin numerar y se ha hecho posteriormente de forma manuscrita. No se ha encontrado una explicación concluyente a la existencia de una hoja con signatura « $\mathrm{N}_{2}$ » que está pegada en escartivana al siguiente cuadernillo «O» y en cuanto al contenido es una continuación de la Salve que se inicia en la hoja « $\mathrm{M}_{6 \mathrm{v}}$ ".

Encuadernado en pergamino flexible de la época, con ornamentación geométrica a tinta en la cubierta y contracubierta.

Exlibris manuscrito en la contracubierta: "Este libro es de la santa iglesia angelical y apostólica metropolitana y primera catedral de Zaragoza", de donde se desprende que perteneció a la basílica catedral del Pilar y no a la Seo, la catedral del Salvador ${ }^{8}$.

Zaragoza, Archivo de Música de las Catedrales de Zaragoza. E-Zac, C-3A. No se dispone en internet de reproducción digitalizada.

\subsubsection{Descripción material}

El volumen presenta papel de calidad, con una marca de agua que reproduce una especie de racimo de uva, con forma romboidal, y no lleva letras. Los tipos utilizados son correctos, la composición es aceptable y la impresión es regular, aunque en ocasiones la tinta pasa de una cara del pliego a la otra, especialmente en el caso de las capitulares. En resumen, es una impresión tan modesta como digna, que se podría calificar de aceptable, pero alejada técnicamente de las obras que se publicaban en los talleres especializados en este tipo de ediciones musicales. Está impreso a una tinta, cuando con frecuencia en estas publicaciones se empleaban dos, al menos en la portada y con menor frecuencia en las páginas interiores, en las que el pentagrama y las cabeceras iban en rojo, mientras que los signos musicales y el texto cantado en negro. Ya se ha adelantado que los folios impares, en una cabecera con orla tipográfica renacentista, presentan el nombre del autor: "Michaelis Navarri", y los pares, en una orla similar, el título de la correspondiente composición musical. Como es práctica general en los libros con obras polifónicas como el presente, la música debía empezar en lo que se considera página par, o folio verso, puesto que ocupa las páginas enfrentadas del libro abierto; así, por ejemplo, cuando reproduce una composición a cuatro voces, en el folio verso se encuentran las partes del "Cantus" y "Altus" mientras que en el recto las del "Bassus" y "Tenor".

Cada folio contiene doce pentagramas, y en cada uno de ellos aparecen entre 30 y 33 signos musicales; los textos cantados van debajo, en letra redonda. En la imprenta de esta época, por lo general, cada tipo musical incluye la parte del pentagrama que le corresponde, lo cual supone la ventaja de que la impresión se hace de una sola vez, con lo que se gana en rapidez y economía, aunque presenta las desventajas de que la lectura es más incómoda pues solo hay una tinta, y de que la pauta musical no forma una línea totalmente recta, una deficiencia del "registro" tipográfico que salta a la vista en el Liber Magnificarum. La notación es mensural de polifonía, con signos romboidales blancos, la empleada comúnmente en obras de estas características. Como es habitual en los libros de coro, cada parte vocal se inicia con una capitular ornada o, más raramente, con la letra de inicio del texto cantado inserta en una orla tipográfica que, en cualquier caso, ocupa el espacio de dos pentagramas; solo en contadas ocasiones la capitular es tan pequeña que requiere e espacio de un pentagrama. Destaca la utilización preferente de un juego de capitulares - su tamaño es de $27 \mathrm{~mm}$ de alto por 46 de base-, las cuales, dentro de un recuadro, muestran la letra mayúscula en positivo, en blanco, sin entintar, sobresaliendo sobre un fondo vegetal abigarrado en el que habita un amorcillo que se encarama en la letra y que, en ocasiones, lleva una lira o comparte el espacio con un ave. La letra más empleada es la "G" - la primera del "Gloria" que cierra frecuentemente las composiciones- y de ella se dispone de tres tacos, pues se comprueba que cuando en el mismo folio se precisan cuatro letras, la última pertenece a otro juego (Fig. 1). 


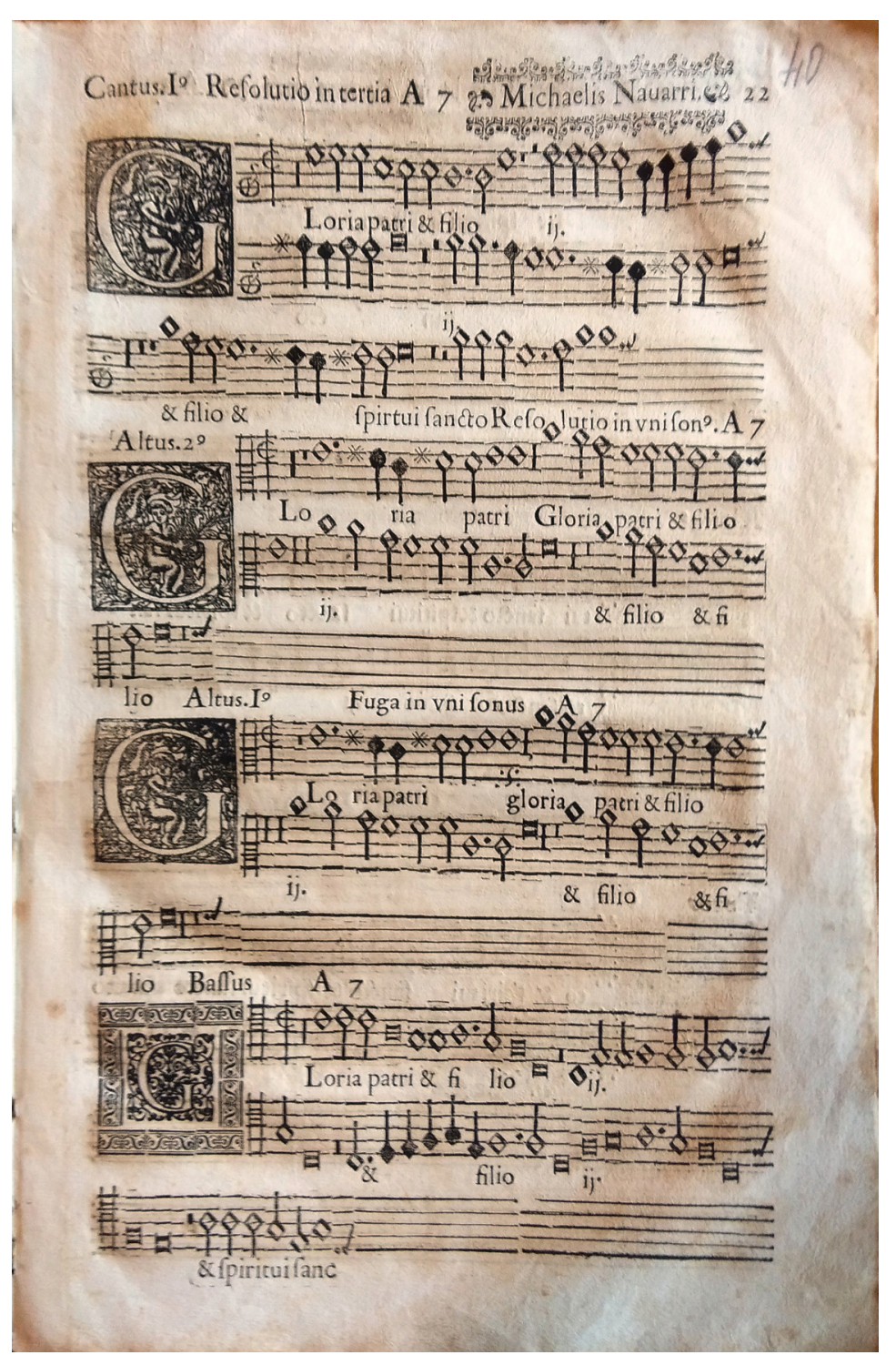

Fig. 1: Capitulares xilográficas, Liber Magnificarum, ejemplar de Tarazona, fol. 22. (Tarazona, Archivo Capitular de la Catedral. Libros de Música, 9)
Llama la atención que las iniciales de estilo renacentista aquí descritas, por estos mismos años, también se empleaban en talleres aragoneses, como el de Juan Pérez de Valdivielso ${ }^{9}$ en Huesca y en los de Juan Lanaja y Quartanet y Pedro Cabarte en Zaragoza ${ }^{10}$. Carlos Labayen las debió de traer de la capital aragonesa, juntamente con el utillaje que había heredado de su suegro Alonso Rodríguez; sea como fuere, las utilizó en sus primeros trabajos en Pamplona, como en la Primera parte de las postrimerías del hombre del mercedario Pedro de Oña, impresa en $1608^{11}$, seis años antes que el libro de Miguel Navarro. Hay que destacar que el volumen carece de los preliminares legales, imprescindibles entonces para la puesta a la venta de un libro, como eran la licencia, el privilegio, la fe de erratas y la tasa. En lo que concierne al contenido, el autor dedica su obra, formada en su totalidad por composiciones marianas, a la Virgen María - Virgini Matri Caelorum Terrarumque Reginae-, a la que la consagra - Meaque omnia dico \& consecro (fol. 1r) - . Todo está en latín, en un texto de 22 líneas de letra redonda, iniciado con una "C" capitular figurada. Seguidamente, bajo un filete, en cursiva, incluye el poema latino de seis versos: Ad Beatam Virginem. Tras la dedicatoria se publican un Magníficat en ocho tonos para los versos impares - Anima mea-, otro también en ocho tonos para los versos pares ${ }^{12}-$ Et exultavit-, una Salve, que Sagaseta considera "bellísima"13, y dos motetes —en total de 19 composiciones-, para concluir con el índice de la obra (Fig. 2).

BALAGUER SÁNCHEZ, F: "El impresor Juan Pérez de Valdivielso (1565-1617), Argensola, 1997, nº 11 pp. 191-204

10 A manera de ejemplo se pueden citar las siguientes ediciones: JIMENEZ, J.: Institutionum medicarum. Huesca, Juan Pérez de Valdivielso, 1578. http://alfama.sim.ucm.es/dioscorides/consulta_libro.asp?re$\mathrm{f}=\mathrm{X} 532761102$ \&idioma $=0$. (Consultado el 3/12/2019), BATISTA DE LANUZA, J. Tractatuum Evangeliorum Zaragoza, Juan de Lanaja y Quartanet, 1612. https://books google es/books?id=6kmu7H-W MoC\&printsec=fron (Cons ro Cabarte, 1624 https://books.google.es/books/ucm?vid=UCM5320775366\&printsec $=$ frontcover\&redir_esc $=y \# v=0$ nepage\&q\&f=false (Consultado el 3/12/2019).

11 ONA, P.: Primera parte de las postrimerías del hombre. Pamplona, Carlos Labayen, 1608. https://books. google.es/books/ucm?vid=UCM532503718X\&printsec=frontcover\&redir_esc=y\&hl=es\#v=onepage\&q\&f=false (Consultado el 8/10/2019)

12 SAGASETA ARÍZTEGUI, A.: Miguel Navarro (ca. 1563-1627). Opera Omnia. Pamplona, Capilla de Música de la Catedral de Pamplona, 2006, p. 21. Afirma que "añade" cinco nuevos magníficats a los del ejemplar de Tarazona, cuando es lo contrario, pues en este último se han suprimido los cinco magníficats de versos impares de cuarto, quinto, sexto, séptimo y octavo tono, que aparecen en el ejemplar de Zaragoza, con el fin de incluir los salmos.

13 Ibid., p. 21. 


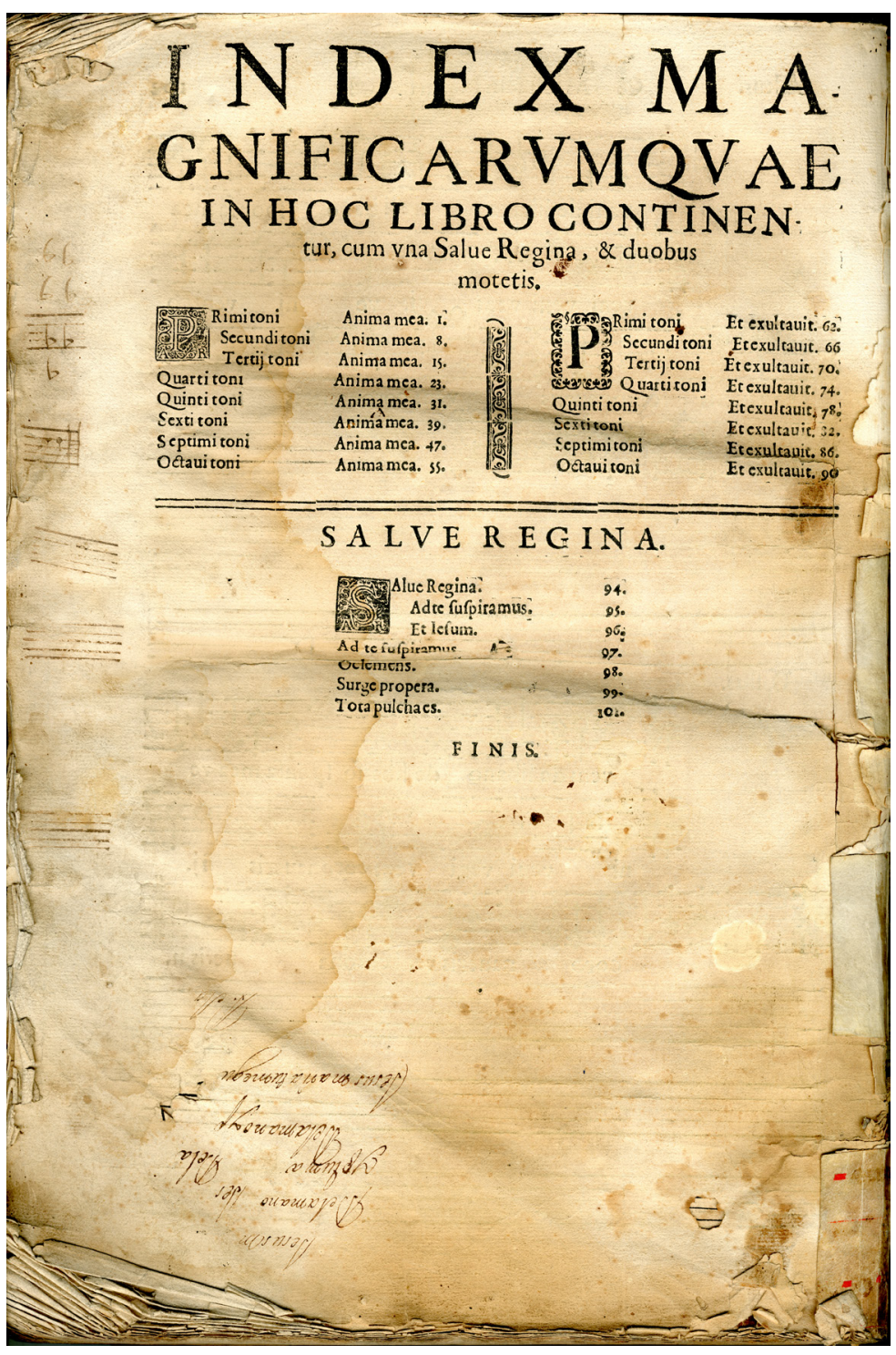

2: Índice del Liber Magnificarum, ed. Zaragoza, fol. 103v. (Zaragoza, Archivo de Música de las Catedrales de Zaragoza. E-Zac, C-3A)
El tema del Magníficat que ocupa buena parte del volumen recibía especial atención por parte los compositores españoles de la época; en este sentido la publicación de Miguel Navarro tiene un precedente cercano - coincide incluso en el título: Liber Magnificarumen la obra de Sebastián de Vivanco, maestro de capilla de la catedral de Salamanca que, en 1607, siete años antes de la aparición de la edición que nos ocupa, ve la luz en la imprenta salmantina de Artus Taberniel. Se trata también de un libro de coro, de 270 páginas, que reúne 18 magníficats $^{14}$.

La Tabla 1 recoge las 19 composiciones que contiene el ejemplar del Liber Magnificarum de Zaragoza, e incluye además la portada - desaparecida-, la dedicatoria y el índice. En las cuatro columnas siguientes se recogen las signaturas tipográficas, la foliación - tanto la impresa como la real- y finalmente el número de los folios de los distintos apartados del volumen.

\subsection{Ejemplar de Tarazona}

El Liber Magnificarum del archivo de la catedral de Tarazona ${ }^{15}$ conserva la portada (Fig. 3) en la que se lee:

"LIBER MAGNI / FICARVM, QVATVOR / VOCIBVS CVM VERSIBVS SE- / nis, septenis, ac octonis, \& fugis, duobus tribus \& /, quatuor simul concinnatis, /AVCTORE / Michaèle Navarro : Pampilonensi Coro Magistro, Summo ingenio, ad Artem / Musicam excogitatus. [Grabado xilográfico de la Anunciación] / CVM PERMISSO SVPERIORUM. /[Filete] Pampilonensi: Ex oficina Caroli â Labâyen, Anno 1614".

Se adorna con un grabado xilográfico a toda plana de la Anunciación del arcángel Gabriel a María ambientada en un entorno arquitectónico renacentista, en el que destacan rasgos flamencos, como pueden ser las marcadas líneas de fuga del pavimento y los pliegues en zigzag de los ropajes. El taco, que está reaprovechado, ya que se ha mutilado en la base, en los ángulos izquierdo y derecho, presenta una ejecución torpe, de deficiente calidad,

14 VIVANCO, S.: Liber Magnificarum. Salamanca, A. Taberniel, 1607. http://contrapunto.uva.es/node/511?language $=$ en (Consultado el 15/10/2019).

15 Mi agradecimiento a Miguel Antonio Franco Garza (Canónigo archivero bibliotecario de la Catedral de Tarazona) por las facilidades ofrecidas para la consulta de este ejemplar. 


\begin{tabular}{|c|c|c|c|c|}
\hline \multirow{2}{*}{ Contenido } & \multirow{2}{*}{ Signaturas tipográficas } & \multicolumn{3}{|c|}{ Foliación } \\
\hline & & Impresa & Real & Suma \\
\hline Portada (Falta) & {[]$_{1} \mathrm{r}$} & & {$[1 \mathrm{r}]$} & 1 \\
\hline En blanco & {[]$_{1} \mathrm{v}$} & & {$[1 \mathrm{v}]$} & \\
\hline Dedicatoria & $A_{1} r$ & $1 \mathrm{r}$ & {$[2 \mathrm{r}]$} & 1 \\
\hline Magnificat ocho tonos (Versos impares) & $\mathrm{A}_{1} \mathrm{v}-\mathrm{H}_{6} \mathrm{r}$ & $1 v-62 r$ & {$[2 \mathrm{v}]-62 \mathrm{r}$} & 61 \\
\hline Magnificat ocho tonos (Versos pares) & $\mathrm{H}_{6} \mathrm{v}-\mathrm{M}_{6} \mathrm{r}$ & $62 \mathrm{v}-93 \mathrm{r}$ & $62 \mathrm{v}$-[i.e. $94 \mathrm{r}$ ] & 32 \\
\hline Salve Regina & $\mathrm{M}_{6} \mathrm{v}+\mathrm{N}_{2} \mathrm{v}+\mathrm{O}_{1} \mathrm{r}-\mathrm{O}_{5} \mathrm{r}$ [i.e. $\mathrm{O}_{4} \mathrm{r}$ ] & $93 v-98 r$ & {$[94 \mathrm{v}-99 \mathrm{r}]$} & 5 \\
\hline Surge propera & $\mathrm{O}_{5} \mathrm{v}$ [i.e. $\mathrm{O}_{4} \mathrm{v}$ ] $-\mathrm{P}_{2} \mathrm{r}$ & $98 v-100 r$ & {$[99 \mathrm{v}-101 \mathrm{r}]$} & 2 \\
\hline Tota pulchra & $\mathrm{P}_{2} \mathrm{v}-\mathrm{P}_{4} \mathrm{r}$ & $100 \mathrm{v}-102 \mathrm{r}$ & {$[101 v-103 r]$} & 2 \\
\hline Index & $\mathrm{P}_{4} \mathrm{v}$ & $102 \mathrm{v}$ & {$[103 v]$} & \\
\hline Total composiciones: 19 & & \multicolumn{3}{|c|}{ Total folios: 104} \\
\hline
\end{tabular}

Tabla 1: Liber Magnificarum, ejemplar de Zaragoza. Fuente: Elaboración propia

\section{Observaciones}

[ ] $-\mathrm{A}_{1} \mathrm{r}=$ Portada (falta en el ejemplar $)+$ Dedicatoria $=(1+1)=2$ hojas A $\mathrm{v}-\mathrm{H} \mathrm{r}=$ Magnificat 8 tonos (Versos impares: Anima mea) $=61$ hojas $\mathrm{H}_{6} \mathrm{v}-\mathrm{M}_{6} \mathrm{r}=$ Magnificat 8 tonos (Versos pares: Et exultavit) $=32$ hojas $\mathrm{M}_{6} \mathrm{v}+\mathrm{N}_{2}+\mathrm{O}_{1}-\mathrm{O}_{4} \mathrm{r}=$ Salve Regina $=(1+4)=5$ hojas

$\mathrm{O}_{4} \mathrm{v}-\mathrm{P}^{4}=$ Motetes $(\operatorname{dos})+\operatorname{Index}=(2+2)=4$ hojas 


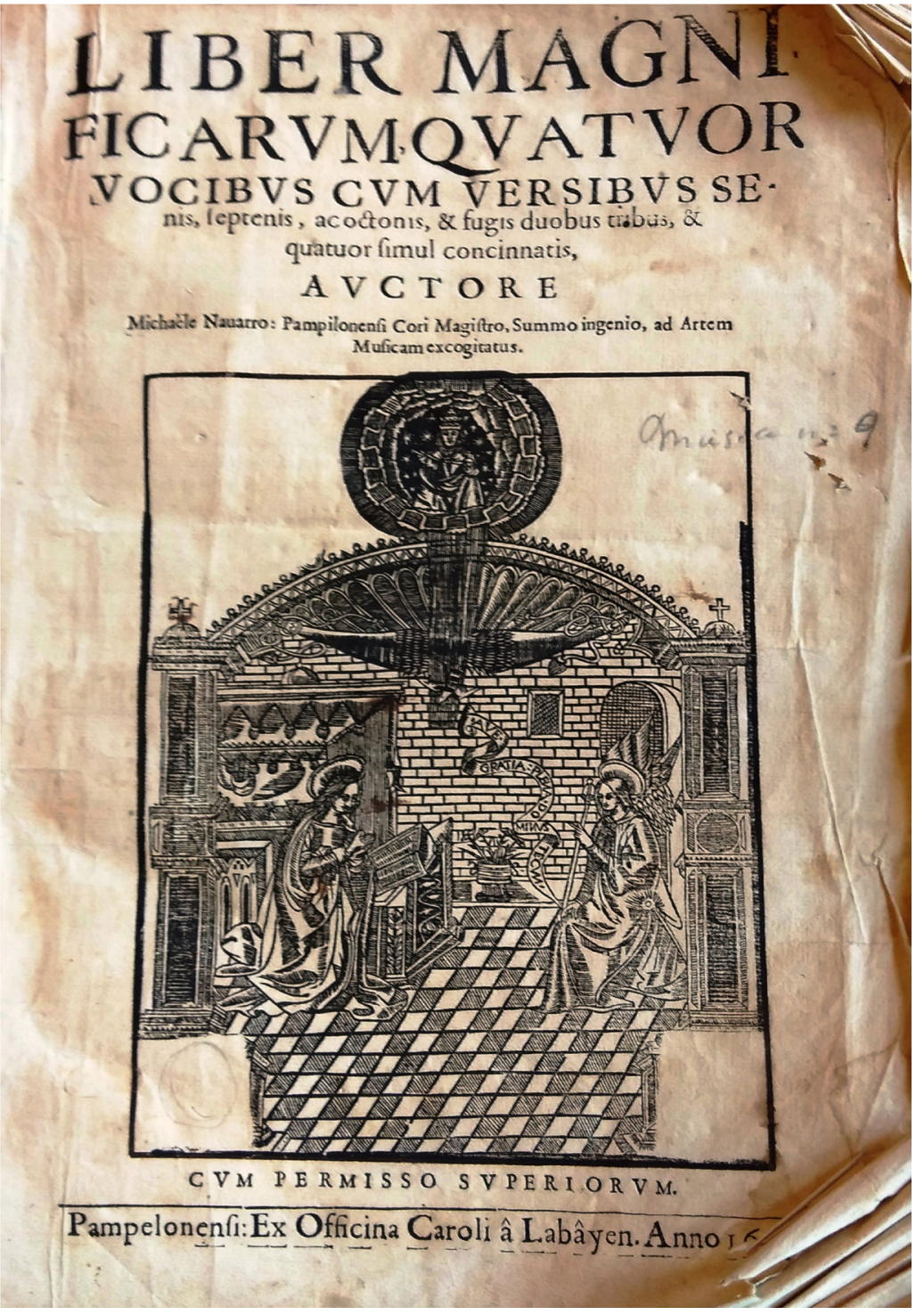

ig. 3: Portada del Liber Magnificarum, ejemplar de Tarazona (Tarazona, Archivo Capitular de la Catedral. Libros de Música, 9) como se comprueba en la rudimentaria perspectiva, en la tosquedad en los detalles arquitectónicos o en la representación poco convencional de Dios Padre. No se conoce el empleo de esta xilografía con anterioridad en los talleres navarros y tampoco se localiza en impresos posteriores, cuando la práctica habitual era reutilizar los tacos xilográficos con propósito ornamental, viniera a cuento o no el tema que representaban. De hecho, así sucede en este caso, pues la ilustración reproduce la Anunciación, cuando este pasaje evangélico no tiene relación con los temas musicales publicados; en cambio, hubiera sido más adecuado recurrir al de la Visitación de la Virgen a su prima santa Isabel, ocasión en la que María pronunció el Magníficat que precisamente da título al volumen ${ }^{16}$.

Gracias a la portada de este ejemplar se comprueba que, tres años después de la muerte de Tomás Luis de Victoria en 1614, tal y como se anuncia en el pie de imprenta, ve la luz en el taller pamplonés de Carlos Labayen el Liber Magnificarum, que, ocupado en su práctica totalidad por composiciones religiosas polifónicas, recoge obras compuestas con "summo ingenio" por Michaele Navarro, maestro de la capilla de la catedral de Pamplona. A continuación, figura la dedicatoria a la Virgen María (Fig. 4), que en la forma y el contenido es igual al ejemplar de Zaragoza. Como sucede en el Liber Magnificarum de Zaragoza, aquí tampoco se publican los preliminares legales. Cabe precisar que en la portada se anuncia que la obra cuenta con el permiso de los superiores - Cum permisso superiorum-, aunque, como era obligado en los clérigos, se referiría a los superiores eclesiásticos del autor, que era sacerdote. Presenta formato en folio, tiene 103 hojas $^{17}$, con errores en la signaturización y foliación como el ejemplar de Zaragoza. Fue descrito por vez primera por Higinio Anglés, en 1941, quien precisó que era una "obra completamente desconocida hasta hoy"18.

16 Lucas (1,39-56)

17 SAgaSETA ARízTEgUi, A.: Miguel Navarro (ca. 1563-1627). Opera Omnia. Pamplona, Capilla de Música de la Catedral de Pamplona, 2006, p. 21, nota 62. Escribe que tiene 168 folios, que le faltan las cinco primeras hojas y las dos últimas, y que la encuadernación es de tapas de madera y piel, lo cual se contradice con los datos aquí aportados tras realizar la colación del ejemplar.

18 ANGLÉS, H.: La música española desde la Edad Media hasta nuestros días. Catálogo de la exposición histórica celebrada en conmemoración del primer centenario del nacimiento del maestro Felipe Pedrell. Barcelon Bibition tular de Tazenala 2 ff. s.n. . 102, chan en An de Tarazona (Catálogo de libros manuscritos, incunables y de música)", Cuadernos de Historia Jerónimo Zurita, n $47-48,1983$, p. 465, nota 9. En la colación señala que tiene 102 folios, cuando son 103. 


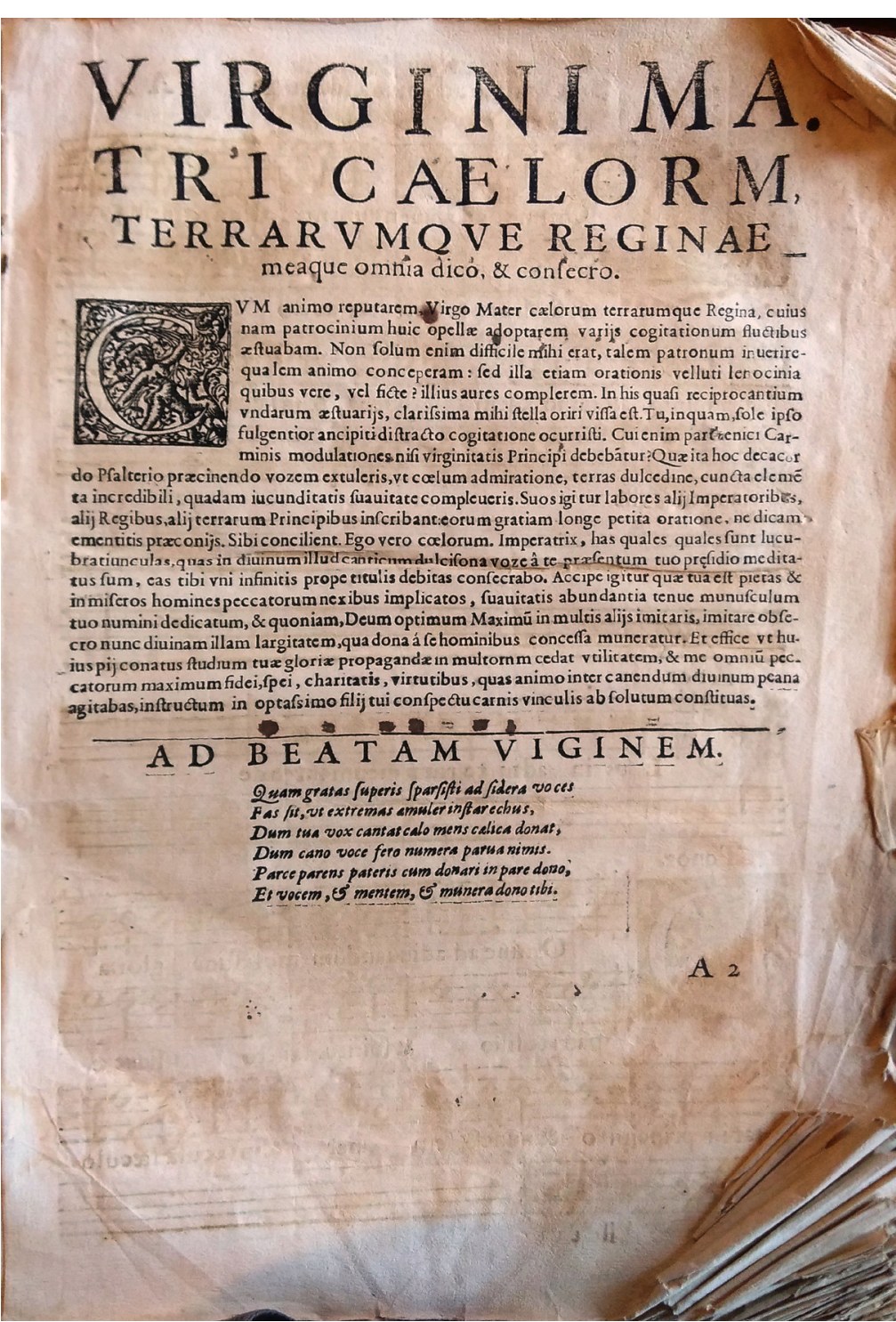

iig. 4: Dedicatoria del Liber Magnificarum, ejemplar de Tarazona, fol. 2r (Tarazona, Archivo Capitular de la Catedral. Libros de Música, 9)

\subsubsection{Colación}

A-B ${ }^{8}, C^{4}, A-I^{8}, K^{1},[]_{1}+N_{2}, O-P^{4}=(20+72+1+1+1+8)=103$ hojas o folios. [2], 102 [i.e. 101] h.: principalmente notación musical; Fol. $(43 \times 29 \mathrm{~cm})$.

Presenta las mismas erratas de signaturización que el ejemplar de Zaragoza, a saber: $« \mathrm{~F}_{5}$ [i.e. $\left.\mathrm{F}_{3}\right] », « \mathrm{H}_{5}$ [i.e. $\left.\mathrm{H}_{4}\right] », \ll \mathrm{O}_{3}-\mathrm{O}_{5}$ [i.e. $\left.\mathrm{O}_{2}-\mathrm{O}_{4}\right] »$.

En cuanto a las erratas de foliación: 2 [i.e. 20], ocho hojas sin numerar [i.e. 21-28], 1173 [i.e. 29-91], una hoja sin numerar [i.e. 92], 94-102 [93-101]. Obviando la portada y dedicatoria sin foliar, en realidad presenta dos series de foliación numerada, la primera de 19 hojas con numeración correlativa en las que contiene los salmos, y una segunda serie de 82 hojas con el Magníficat de versos impares Anima mea de ocho tonos y los tres primeros tonos del Magníficat de versos pares Et exultavit, así como la Salve y los dos motetes. Los pliegos impresos de esta segunda serie son los utilizados para la edición del ejemplar de Zaragoza, por lo que las erratas que se producen son las mismas.

Encuadernación semejante al ejemplar de Zaragoza, en pergamino flexible de la época, con ornamentación geométrica a tinta en la cubierta y contracubierta.

Archivo de la catedral de Tarazona. Libros impresos de Música, nº 9. No se dispone en internet de reproducción digitalizada

\subsubsection{Descripción materia}

El volumen recoge 22 composiciones musicales - el de Zaragoza tiene 19-: un canto introductorio -Domine adiuvandum - , siete salmos; el Magníficat en ocho tonos para versos impares - el mismo que el del ejemplar de Zaragoza-, los tres primeros tonos del Magníficat en ocho tonos para versos pares de Zaragoza; para concluir con la Salve y dos motetes que también aparecen en el ejemplar de Zaragoza. La Tabla 2 recoge las obras que contiene, además de la portada, dedicatoria e índice; muestra las signaturas tipográficas y la foliación: impresa, manuscrita — realizada muy posteriormente a la obra impresa - y la real. Concluye con la suma de los folios de cada una de las composiciones. 


\begin{tabular}{|c|c|c|c|c|c|}
\hline \multirow{2}{*}{ Contenido } & \multirow{2}{*}{ Signaturas tipográficas } & \multicolumn{4}{|c|}{ Foliación } \\
\hline & & Impresa & Manuscrita & Real & Suma \\
\hline Portada & {$[\mathrm{A}]_{1} \mathrm{r}$} & & & {$[1 \mathrm{r}]$} & 1 \\
\hline En blanco & {$[\mathrm{A}]_{1} \mathrm{~V}$} & & & {$[1 \mathrm{v}]$} & 0 \\
\hline Dedicatoria & $\mathrm{A}_{2} \mathrm{r}$ & & & {$[2 \mathrm{r}]$} & 1 \\
\hline Domine adiuvandum & $\mathrm{A}_{2} \mathrm{v}-\mathrm{A}_{3} \mathrm{r}$ & $1 \mathrm{r}$ & & {$[2 \mathrm{v}]-1 \mathrm{r}$} & 1 \\
\hline Dixit Dominus Domino meo & $\mathrm{A}_{3} \mathrm{v}-\mathrm{A}_{6} \mathrm{r}$ & $1 \mathrm{v}-4 \mathrm{r}$ & & $1 \mathrm{v}-4 \mathrm{r}$ & 3 \\
\hline Beatus vir & $\mathrm{A}_{6} \mathrm{v}-\mathrm{B}_{1} \mathrm{r}$ & $4 v-7 \mathrm{r}$ & & $4 \mathrm{v}-7 \mathrm{r}$ & 3 \\
\hline Laudate pueri & $\mathrm{B}_{1} \mathrm{v}-\mathrm{B}_{4} \mathrm{r}$ & $7 \mathrm{v}-10 \mathrm{r}$ & & $7 \mathrm{v}-10 \mathrm{r}$ & 3 \\
\hline Laudate Dominum & $\mathrm{B}_{4} \mathrm{v}-\mathrm{B}_{5} \mathrm{r}$ & $10 \mathrm{v}-11 \mathrm{r}$ & & $10 \mathrm{v}-11 \mathrm{r}$ & 1 \\
\hline Letatus sum & $\mathrm{B}_{5} \mathrm{v}-\mathrm{B}_{8} \mathrm{r}$ & $11 \mathrm{v}-14 \mathrm{r}$ & & $11 \mathrm{v}-14 \mathrm{r}$ & 3 \\
\hline Lauda Hierusalem & $\mathrm{B}_{8} \mathrm{v}-\mathrm{C}_{3} \mathrm{r}$ & $14 \mathrm{v}-17 \mathrm{r}$ & & $14 \mathrm{v}-17 \mathrm{r}$ & 3 \\
\hline Nisi Dominus & $\mathrm{C}_{3} \mathrm{v}-\mathrm{A}_{1} \mathrm{r}$ & $17 \mathrm{v}-19 \mathrm{r}$ & & $17 \mathrm{v}-19 \mathrm{r}$ & 2 \\
\hline Magnificat ocho tonos (Versos impares) & $\mathrm{A}_{1} \mathrm{v}-\mathrm{H}_{6} \mathrm{r}$ & $19 \mathrm{v}-62 \mathrm{r}$ & $19 v-80 \mathrm{r}$ & {$[19 \mathrm{v}-80 \mathrm{r}]$} & 61 \\
\hline Magnificat tres tonos (Versos pares) & $\mathrm{H}_{6} \mathrm{v}-\mathrm{K}_{1} \mathrm{v}$ & $62 \mathrm{v}-73 \mathrm{v}$ & $80 \mathrm{v}-91 \mathrm{v}$ & {$[80 \mathrm{v}-91 \mathrm{v}]$} & 11 \\
\hline En blanco & {[]$_{1} \mathrm{r}$} & & $93 r$ & {$[92 \mathrm{r}]$} & 1 \\
\hline Salve Regina & []$_{1} \mathrm{v}+\mathrm{N}_{2}-\mathrm{O}_{5} \mathrm{r}$ [i.e. $\left.\mathrm{O}_{4} \mathrm{r}\right]$ & sin num. $+94 r-98 r$ & $93 \mathrm{v}-98 \mathrm{r}$ & {$[92 \mathrm{v}-97 \mathrm{r}]$} & 5 \\
\hline Surge propera & $\mathrm{O}_{5} \mathrm{v}$ [i.e. $\left.\mathrm{O}_{4} \mathrm{v}\right]-\mathrm{P}_{2} \mathrm{r}$ & $98 \mathrm{v}-100 \mathrm{r}$ & $98 \mathrm{v}-100 \mathrm{r}$ & {$[97 \mathrm{v}-99 \mathrm{r}]$} & 2 \\
\hline Tota pulchra & $\mathrm{P}_{2} \mathrm{v}-\mathrm{P}_{4} \mathrm{r}$ & $100 \mathrm{v}-102 \mathrm{r}$ & $100 \mathrm{v}-102 \mathrm{r}$ & {$[99 \mathrm{v}-101 \mathrm{r}]$} & 2 \\
\hline Index & $\mathrm{P}_{4} \mathrm{v}$ & $102 \mathrm{v}$ & $102 \mathrm{v}$ & $101 \mathrm{v}$ & 0 \\
\hline Total composiciones: 22 & & & Total folios: & & \\
\hline
\end{tabular}

Tabla 2: Liber Magnificarum, ejemplar de Tarazona. Fuente: Elaboración propia 
Al final del volumen aparece el índice (Fig. 5) en el que llama la atención que no figura la foliación de las 19 primeras obras - el canto introductorio, los salmos y los magníficats- y sí la de la Salve y los motetes, que, al igual que el ejemplar de Zaragoza, comienzan en el folio 94 .

\subsection{Coincidencias y diferencias}

Los ejemplares de Zaragoza y Tarazona emplean el mismo papel, tienen el mismo formato, utilizan una sola tinta y los mismos tipos y capitulares; la composición de la página es idéntica y presentan los mismos errores en la signaturización y foliación. Finalmente, la calidad de la impresión es semejante: aceptable. Sin embargo, por lo que se refiere al contenido muestran coincidencias y diferencias: en relación con el ejemplar de Zaragoza, el de Tarazona repite la Salve, los dos motetes, el Magníficat ocho tonos para versos impares y los tres primeros tonos del Magníficat para versos pares, pero incluye como novedad un canto introductorio y siete salmos. En resumen, el de Zaragoza contiene 19 composiciones musicales y el de Tarazona 22, de las cuales ocho son nuevas, las cuales suponen el 18,4 por ciento del total de la foliación de este volumen. ¿Por qué en el ejemplar de Tarazona se suprimieron los cinco últimos tonos del Magníficat de versos pares? Porque de esta manera se recuperaron veinte folios que se destinaron a incluir los siete salmos y el canto introductorio que no figuraban en el ejemplar de Zaragoza. Como ya se ha expuesto, en el ejemplar de Tarazona se utilizaron, para las obras que se repetían, los mismos pliegos impresos que se habían empleado en el de Zaragoza.

Cabe suponer que la portada del ejemplar de Zaragoza era la misma que luce el de Tarazona, ya que su título Liber Magnificarum se ajusta más a su contenido -comienza con 16 magníficats-, mientras que el de Tarazona principia con salmos; por este motivo su título más adecuado sería del de Liber psalmorum, de conformidad con el encabezamiento del índice: Index psalmorum. Si se tiene presente la diferencia en los contenidos y consiguientemente en la paginación de los dos ejemplares (Tabla 3), cabe concluir que el ejemplar de Zaragoza fue el primero en aparecer y el de Tarazona vio la luz después, posiblemente tras un corto espacio de tiempo, por lo que puede ser considerado como un "variante de edición", descartando la posibilidad de que se trate de una emisión y, menos, de una nueva edición.

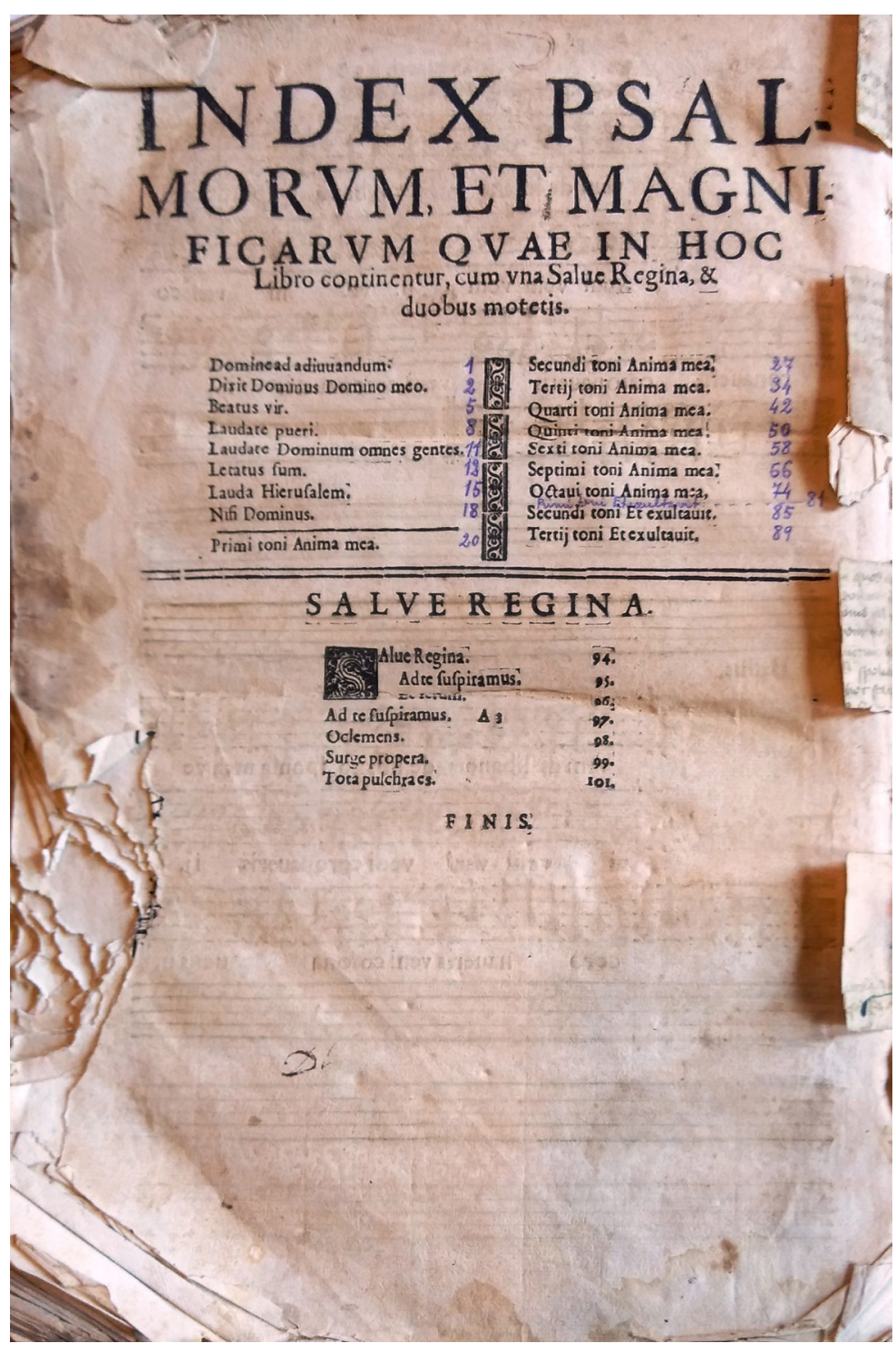

Fig. 5: Índice del Liber Magnificarum, ejemplar de Tarazona, fol. 101v (Tarazona, Archivo Capitular de la Catedral) 


\begin{tabular}{|c|c|c|c|c|c|c|c|}
\hline \multicolumn{4}{|c|}{ Liber Magnificarum, ejemplar de Zaragoza } & \multicolumn{4}{|c|}{ Liber Magnificarum, ejemplar de Tarazona } \\
\hline \multirow[t]{2}{*}{ Composiciones } & \multicolumn{3}{|c|}{ Foliación } & Composiciones & \multicolumn{3}{|c|}{ Foliación } \\
\hline & Impresa & Real & Suma & & Impresa & Real & Suma \\
\hline Portada (Falta) & [1] & {$[1 \mathrm{r}]$} & 1 & Portada & [1] & {$[1 \mathrm{r}]$} & 1 \\
\hline \multirow[t]{9}{*}{ Dedicatoria } & [2] & {$[2 \mathrm{r}]$} & 1 & Dedicatoria & [2] & {$[2 \mathrm{r}]$} & 1 \\
\hline & & & & Domine adiuvandum & {$[2 \mathrm{v}]-1 \mathrm{r}$} & {$[2 \mathrm{v}]-1 \mathrm{r}$} & 1 \\
\hline & & & & Dixit Dominus Domino meo & $1 \mathrm{v}-4 \mathrm{r}$ & $1 \mathrm{v}-4 \mathrm{r}$ & 3 \\
\hline & & & & Beatus vir & $4 v-7 r$ & $4 v-7 r$ & 3 \\
\hline & & & & Laudate pueri & $7 \mathrm{v}-10 \mathrm{r}$ & $7 \mathrm{v}-10 \mathrm{r}$ & 3 \\
\hline & & & & Laudate Dominum & $10 \mathrm{v}-11 \mathrm{r}$ & $10 \mathrm{v}-11 \mathrm{r}$ & 1 \\
\hline & & & & Letatus sum & $11 \mathrm{v}-14 \mathrm{r}$ & $11 \mathrm{v}-14 \mathrm{r}$ & 3 \\
\hline & & & & Lauda Hierusalem & $14 \mathrm{v}-17 \mathrm{r}$ & $14 \mathrm{v}-17 \mathrm{r}$ & 3 \\
\hline & & & & Nisi Dominus & $17 \mathrm{v}-19 \mathrm{r}$ & $17 \mathrm{v}-19 \mathrm{r}$ & 2 \\
\hline Magníficat ocho tonos (Impares) & $1 v-62 r$ & {$[2 \mathrm{v}]-62 \mathrm{r}$} & 61 & Magnificat ocho tonos (Impares) & $19 v-62 r$ & {$[19 v-80 r]$} & 61 \\
\hline Magnificat ocho tonos (Pares) & $62 \mathrm{v}-93 \mathrm{r}$ & $62 \mathrm{v}$-[i.e. $94 \mathrm{r}$ ] & 32 & Magnificat tres tonos (Pares) & $62 \mathrm{v}-73 \mathrm{v}$ & {$[80 v-91 v]$} & 11 \\
\hline Salve Regina & $93 \mathrm{v}-98 \mathrm{r}$ & {$[94 \mathrm{v}-99 \mathrm{r}]$} & 5 & Salve Regina & 1 sin num. $+94 r-98 r$ & {$[92 \mathrm{v}-97 \mathrm{r}]$} & 6 \\
\hline Surge propera & $98 \mathrm{v}-100 \mathrm{r}$ & {$[99 \mathrm{v}-101 \mathrm{r}]$} & 2 & Surge propera & $98 \mathrm{v}-100 \mathrm{r}$ & {$[97 \mathrm{v}-99 \mathrm{r}]$} & 2 \\
\hline Tota pulchra & $100 \mathrm{v}-102 \mathrm{r}$ & {$[101 v-103 r]$} & 2 & Tota pulchra & $100 \mathrm{v}-102 \mathrm{r}$ & {$[99 \mathrm{v}-101 \mathrm{r}]$} & 2 \\
\hline Î́ndice & $102 \mathrm{v}$ & {$[103 v]$} & 0 & Índice & $102 \mathrm{v}$ & [101v] & 0 \\
\hline Total composiciones: 19 & & tal folios: 104 & & Total composiciones: 22 & Total & olios: 103 & \\
\hline
\end{tabular}

Tabla 3: Liber Magnificarum, coincidencias y diferencias en el contenido y la foliación de los ejemplares de Zaragoza y Tarazona. Fuente: Elaboración propia 


\subsection{Falta de preliminares legale}

Como se ha expuesto, en aquella época toda obra que se pretendiera imprimir necesitaba obtener la licencia de impresión, el privilegio que marcaba el tiempo de los derechos de autor, la tasa que establecía el precio de venta y la fe de erratas que dejaba constancia de que la tirada reproducía sin cambios el original manuscrito autorizado, en este caso, por el Consejo Real de Navarra ${ }^{19}$. El hecho de que los dos ejemplares no incluyan los permisos legales se podría deber a que no estaban destinados a la distribución comercial sino a mecenas, o a servir de muestras comerciales para posibles compradores o para ofrecerlos como donación. Knighton pone de relieve que, en esta época:

"En la Península Ibérica la distribución de libros de música, en especial las colecciones de polifonía sacra, era competencia del compositor que las había mandado imprimir, posiblemente con la intención de disponer de una publicación de prestigio que aumentara su fama o de la institución eclesiástica a la que pertenecía, y también como una aventura comercial de la que a lo sumo esperaría recuperar el gasto ofreciendo el volumen a otras catedrales e iglesias" 20

Este pudo ser el caso de Miguel Navarro, que encargaría la impresión de sus composiciones musicales con fines de promoción personal, dado que la catedral de Pamplona no figura como mecenas, ni es el objeto de la dedicatoria de la publicación, ni existe mención de gratitud por su posible mecenazgo, y, al parecer, no adquirió un solo ejemplar impreso. En el caso presente la difusión debió de ser restringida y al margen de los cauces comerciales, por este motivo el autor-editor encargaría impresiones únicas o de tirada muy reducida para las que no sería imprescindible recabar los permisos de edición. Esta circunstancia - la tirada extraordinariamente corta - explicaría que en solo se conozcan los dos ejemplares estudiados, que, además, son diferentes. Apoya lo expuesto la noticia de que Miguel Navarro envió un volumen impreso con sus composiciones al cabildo de la catedral de Burgos, el cual, el 27 de noviembre de 1615 — al año siguiente de la publicación del Liber Magnificarum -, acordó que el fabriquero y el maestro de capilla informaran sobre la

19 ITÚRBIDE DÍAZ, J.: Los libros de un Reino: Historia de la edición en Navarra (1490-1841). Pamplona Gobierno de Navarra, 2015, pp. 124-131.

20 KNIGHTON, T.: "Preliminary Thoughts on the Dynamics of Music Printing in the Iberian Peninsula during the Sixteenth Century", Bulletin of Spanish Studies, vol. 89, n 4, 2012, p. 522 conveniencia de su compra ${ }^{21}$. No se sabe si finalmente se adquirió, pero la realidad es que no figura en el Archivo de la catedral ${ }^{22}$. En cuanto al origen de las ediciones de Zaragoza y Tarazona, en los respectivos archivos, no se ha encontrado documentación relativa a su propuesta de compra - como sucedió en Burgos- o de donación.

\section{COLECCIONES MANUSCRITAS CON OBRAS DE MIGUEL NAVARRO}

Las bibliotecas de la de la catedral de Pamplona y de la colegiata de Roncesvalles conservan cuatro libros manuscritos con composiciones musicales de Miguel Navarro; solo uno de ellos está datado - en torno a 1595-, mientras que los restantes se pueden situar por esas mismas fechas: a finales del siglo XVI o comienzos del XVII. De cualquier manera, por su contenido, cabe deducir que son anteriores a la impresión del Liber Magnificarum ${ }^{23}$. La Capilla de Música de la Catedral de Pamplona dispone del Libro de Polifonía 1 dedicado exclusivamente a Miguel Navarro que contiene catorce composiciones, mientras que el Libro de Polifonía 2, reúne obras de diversos autores entre los que figura Miguel Navarro con once. En conjunto los dos códices suman 25 composiciones: 17 salmos, siete magníficats y un canto introductorio ${ }^{24}$. Por su parte la colegiata de Roncesvalles custodia el Libro de Polifonía 1 que está destinado exclusivamente a composiciones de Miguel

21 Archivo de la Catedral de Burgos, reg 76 (1614-1618), fol. 199v. Apud SAGASETA, A.: "El polifonista Michael Navarrus (ca. 1563-1627”) en Música en la Catedral de Pamplona. Pamplona, Catedral, 1983, $\mathrm{n}^{\circ} 1$, p. 14 , nota 47.

22 LÓPEZ-CALO, J.: La música en la catedral de Burgos. Burgos, Caja de Ahorros del Círculo Católico de Burgos, 1995, vols. 1 y 2, Archivo de Música. El catálogo no recoge obra alguna de Miguel Navarro.

23 En 1996 se editó una selección de la obra de Miguel Navarro interpretada por The Scholars y la Capilla de Música de la Catedral de Pamplona bajo la dirección de Aurelio Sagaseta. Música en la catedral de Pamplona 2. Renacimiento. Miguel Navarro. Orio, 1966. 1 CD (96 min.), un folleto (16 p.)

24 SAGASETA ARIZTEGUI, A.: Catálogo del Archivo de Música. Catedral de Pamplona. Vol. I. Fondos históricos. Desde los orígenes hasta 1962. Pamplona Analecta 2015, pp. 29-33. http:/wwwarchivomusihistoricos Desde los ca-catedralo "Lin E.: Libros de polifoni en la Catedral de Pamplona", Pripcipe de Vian, 2006 no 38 pp 343-361. SAGASETA, A.: "El polifonista Michael Navarrus (ca. 1563-1627)” en Música en la Catedral de Pamplona. Pamplona, Catedral, 1983, p. 12 
Navarro, y el Libro de Polifonía 2, el cual, entre otros autores, recoge tres composiciones de este músico ${ }^{25}$. En total ofrecen cuatro salmos, dos magníficats y un canto introductorio. Sagaseta considera que estos libros son copia de los de Pamplona ${ }^{26}$.

El ejemplar de Zaragoza del Liber Magnificarum ofrece la Salve y los dos motetes que no figuran en los libros manuscritos de Pamplona y Roncesvalles, mientras que de los 16 magníficats impresos solo siete están recogidos en los citados manuscritos. Por su parte, de los siete salmos que publica el ejemplar de Tarazona solo uno - Nisi Dominus - no aparece en las colecciones manuscritas de Pamplona y Roncesvalles. Ya se ha apuntado que en el archivo de la Capilla de Música de la catedral de Pamplona no figura el Liber Magnificarum cuyo autor y editor era su titular cuando se imprimió; descartada la posibilidad, relativamente remota, de que se hubiera perdido, es posible que en su momento se desestimara la compra, bien por su precio o porque la catedral ya tenía dos manuscritos con obras del Miguel Navarro.

\subsection{El autor-editor}

En los ejemplares del Liber Magnificarum, como se ha adelantado, figura como autor, en la portada y cabeceras, Miguel Navarro - sus apellidos eran Echarren y Navarro (Fig. 6) ${ }^{27}$ . Había nacido en Pamplona en torno a $1563^{28}$ en una familia con un nivel económico elevado, como se desprende de sus propiedades rústicas y urbanas en torno a la capital.

25 PEÑAS GARCÍA, M. C.: Catálogo de los fondos musicales de la Real Colegiata de Roncesvalles. Pamplona, Gobierno de Navarra, 1995.

26 SAGASETA ARíZTEGUI, A.: Miguel Navarro (ca. 1563-1627). Opera Omnia. Pamplona, Capilla de Música de la Catedral de Pamplona, 2006, p. 8.

27 SAGASETA ARIZTEGUI, A.: "Navarro, Miguel", Diccionario de la música española e hispanoamericana José López-Calo, Ismael Fernández de la Cuesta (Dirs.) Madrid, SGAE, 2000, vol. Maaning-Ñuwinül, p. 994. SAGASETA ARIZTEGUI, A. "Echarren y Navarro, Miguel de", Gran Enciclopedia Navarra. Pamplona, Caja de Ahorros de Navarra, 1990, vol. IV, pp. 149-150. http://www.enciclopedianavarra. com/?page_id=8348 (Consultado el 4/10/2019). SAGASETA, A.: "El polifonista Michael Navarrus (ca. 1563-1627)", Música en la Catedral de Pamplona. Pamplona, Catedral, 1983. Una reseña de esta publicación en Ritmo, no 534, junio 1983, pp. 83-84. LÓPEZ-CALO, J.: "Sagaseta, Aurelio: El polifonista Michael Navarrus (ca. 1563-1627)".

28 GOÑI GAZTAMBIDE, J.: "La adopción de la liturgia tridentina y los libros de coro en la diócesis de Pamplona" Príncipe de Viana, no 24, 1946, p. 570. Prueba documentalmente que Miguel Navarro en 1589 tenía 26 años "poco más o menos"

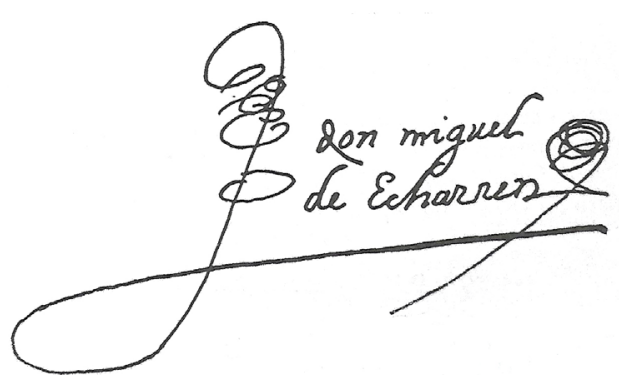

Fig. 6: Firma de "don Miguel de Echarren", es decir: Miguel Navarro (GOÑI GAZTAMBIDE, J. La capilla musical de la catedral de Pamplona. Pamplona, Capilla de Música, 1983, p. 16.)

No se tienen noticias de su formación musical, pero el hecho es que cuando solo tenía unos 22 años, en torno a 1585, ya desempeñaba el cargo de maestro de capilla de la catedral de Pamplona dotado con cien ducados anuales ${ }^{29}$. El 12 de octubre de ese año pretendió sin éxito el mismo cargo en la catedral de Calahorra - lo ganó, superando a tres candidatos, Juan Esquivel de Barahona, que venía de la catedral de Oviedo ${ }^{30}$-, por lo que continuó prestando sus servicios en la catedral de Pamplona. En 1591, de nuevo concursó, juntamente con Juan García Garay y Marcos Esteban, a la plaza de maestro de capilla de la catedral de León y fue superado por el zamorano Alonso de Tejeda, un músico veterano - tenía 23 años más- y con mejor currículum, que al final de su vida presentó una brillante trayectoria como compositor y maestro de capilla de las principales catedrales de España, entre las que se encontraban las de León, Salamanca, Toledo, Burgos

29 GOÑI GAZTAMBIDE, J.: La capilla musical de la catedral de Pamplona. Pamplona, Capilla de Música, 1983, p. 21.

30 RODILLA LEÓN, F.: “Juan Esquivel (de) Barahona” Diccionario Biográfico. Real Academia de la Historia. http://dbe.rah.es/biografias/17977/juan-esquivel-de-barahona (Consultado el 8/10/2019). 
y la capilla real de Granada ${ }^{31}$. También en el mismo año de 1591, el "presbítero" Migue Navarro fue llamado por el cabildo de la catedral de Calahorra para desempeñar el cargo de maestro de capilla. Cuando llevaba dos años en esta ciudad riojana, volvió a concursar, ahora en Salamanca, y por segunda vez fracasó frente a la candidatura de Alonso de Tejeda; en consecuencia, permaneció al servicio de la catedral de Calahorra durante casi nueve años, desde el 15 de junio de 1591 hasta el 23 de enero de $1600^{32}$. En este año su vida dio un giro radical: abandonó su oficio en la catedral de Calahorra, lo que implicaba la renuncia a la "media ración" a la que tenía derecho, para retirarse como ermitaño a la localidad riojana de Turruncún, una población, hoy abandonada, situada en la sierra de Préjano, distante 28 kilómetros de Calahorra, donde hasta ese momento había residido. Fuera de este apartado lugar se encuentra la ermita de las vírgenes Nunilo y Alodia y allí, alejado del mundo, el ermitaño Miguel Navarro permaneció en torno a ocho años, en silencio, "haciendo verdadera penitencia", según exponía en el texto de renuncia al puesto de maestro de capilla de la catedral de Calahorra. Rondaba los 45 años cuando, en 1608 regresó a su tierra natal para ocupar el puesto de segundo maestro de capilla de la catedral de Pamplona, ya que la dirección la venía ostentando desde 1593 Juan de Aldaba. Cuando este falleció en 1616, pasó a desempeñar el de maestro, dotado con 120 ducados anuales ${ }^{33}$, y en este cargo permaneció once años, hasta su fallecimiento en 1627. Por lo que concierne a los 120 ducados de su salario anual, cabe precisar que el cronista del Reino de Navarra, José Moret, medio siglo más tarde, cobraba $150^{34}$.

Tras regresar a Pamplona, no abandonó la vinculación con la vida de anacoreta: entre 1613 y 1616 desempeñó el cargo de prior de la Cofradía de Ermitaños del Obispado de Pamplona, y a ella permanecerá unido hasta el final de sus días, ya que la nombró heredera de sus bienes, entre los que figuraba su casa de Pamplona; con este fin, dispuso en su testamento, pocos días antes de su fallecimiento, que se transformara en albergue para los ermitaños que visitasen la ciudad, donde serían acogidos gratuitamente durante una jornada y atendidos por dos cofrades de vida ejemplar, todo ello para que no se alojaran

31 RODILLA LEÓN, F..: "Alonso de Torres Tejeda" en Diccionario Biográfico. Real Academia de la Historia. http://dbe.rah.es/biografias/17976/alonso-de-torres-tejeda (Consultado el 8/10/2019).

32 PRECIADO, D. "Miguel Navarro, un polifonista que se hizo ermitaño", Revista de Musicologín vol. 6 $\mathrm{n}^{\circ} 1-2,1983$, pp. $423-456$

33 GOÑI GAZTAMBIDE, J.: La Capilla Musical de la Catedral de Pamplona en el siglo XVII. Pamplona Capilla de Música, 1986, p. 16

34 Archivo General de Navarra (AGN). Caja 30879. Sección de Historia y Literatura, legajo 2, carpeta 5. en hospedajes inadecuados ${ }^{35}$. Miguel Navarro, después de los frustrados intentos de prosperar como músico en León y Salamanca, después de ejercer como maestro de capilla en Calahorra y de vivir ocho años como ermitaño, a partir de 1608 su vida personal y su carrera profesional parecen definitivamente asentadas en Pamplona, su ciudad natal donde dispone de un sueldo holgado, casa confortable y rentas saneadas; además, cuenta con los cuidados de Catalina Janáriz, su sirvienta, que le atenderá durante los últimos quince años de su vida.

Es precisamente en la última etapa profesional, en 1614, a los 51 años, cuando encarga al tipógrafo Carlos Labayen imprimir algunas de sus composiciones polifónicas. La publicación en un corto espacio de tiempo, puede que dentro del año 1614, de los dos ejemplares conocidos del Liber Magnificarum debió de ser una experiencia gratificante para el autor-editor, ya que intentó continuar esta actividad haciéndose cargo en el futuro de todo el proceso de elaboración: sentado que disponía de los tipos de imprenta musicales, pretendía contar con prensa propia. Por este motivo, tres años más tarde, en 1617, encargó al cerrajero de Pamplona, Pedro Lazcano, la fabricación de un "husillo de emprenta de hierro", el tornillo que hacía bajar la platina, la plancha de impresión. Lazcano era un profesional de prestigio: en 1603 había sido nombrado "referidor de los pesos y pesas de hierro" del Reino de Navarra, cargo que no le impedía trabajar por su cuenta y "hacer rejas y otras obras de cerrajería" 36 , y posteriormente desempeñó el cargo de "referidor de las pesas de hierro" de la ciudad de Pamplona ${ }^{37}$. Pero Miguel Navarro no quedó satisfecho con el usillo y se negó a pagar los seis ducados que había pactado con el cerrajero. Éste, por su parte, lo denunció ante los tribunales y el músico, en su comparecencia, solicitó que la pieza fuera probada en una prensa por profesionales, asegurando que la abonaría si dictaminaban que era válida ${ }^{38}$. Este litigio debió de disuadirle de contar con imprenta propia; el hecho es que no se conocen ediciones posteriores a las del Liber Magnificarum.

35 Ibid., Procesos, nº 310745. 28-XII-1626. Testamento de Miguel de Echarren, maestro de capilla de la catedral.

36 Ibid., Procesos, nº 72483

37 Ibid., Procesos, no 13773

38 Archivo de la Catedral de Pamplona, Documentos sueltos, 1617. Apud SAGASETA, A. "El polifonista Michael Navarrus (ca. 1563-1627)" en Música en la Catedral de Pamplona. Pamplona, Catedral, 1983, $\mathrm{n}^{\circ}$ 1, p. 14, nota 46. En el catálogo del Archivo de la Catedral de Pamplona no figura la sección "Documentos sueltos" y no hemos localizado este manuscrito en las secciones "Capilla de Música" y "Papeles Varios" en las que podría estar registrado. 
Falleció en su ciudad natal el 12 de enero de $1627^{39}$, a los 64 años. De acuerdo con sus últimas voluntades, fue enterrado en el convento de la Merced, en la capilla de la Virgen de los Dolores, "en la pared donde tengo señalado el sitio y hecha abrir la sepultura". Pidió que a su entierro asistieran la capilla de música de la catedral y "los coristas de la parroquial de ella” —se refería a la parroquia de san Juan Bautista—, y dejó cincuenta ducados para rezar quinientas misas por su alma, con la precisión de que se oficiaran en el mismo año de su muerte ${ }^{40}$. En cuanto a su relevancia musical, Gembero afirma: "La polifonía de Miguel Navarro, de gran calidad y belleza, le sitúa entre los mejores representantes del repertorio

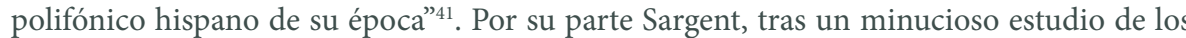
magníficats de Navarro, que contrapone con los de Sebastián de Vivanco y Juan Esquivel Barahona, y de los que asegura que dedicó su "esfuerzo compositivo más sostenido", concluye: "Entre los compositores españoles del bajo Renacimiento que cultivaron la composición de magníficats, el aspecto más destacado del trabajo de Navarro estriba en su decido esfuerzo por equilibrar tradición e innovación”"

\subsection{El impresor}

El impresor y librero Carlos Labayen, que figura en el pie de imprenta de la portada de la edición de Tarazona - "Ex Oficina Caroli â Lâbayen" - tenía taller en la capital navarra desde 1607, cuando procedente de Zaragoza se instaló en Pamplona invitado por el Ayuntamiento ${ }^{43}$ Se había formado profesionalmente en la capital aragonesa, donde en 1604, con 26 años,

39 Archivo Diocesano de Pamplona. Parroquia de San Juan Bautista, Libro de Difuntos no 12, fol. 82v Apud SAGASETA ARÍZTEGUI, A. Miguel Navarro (ca. 1563-1627). Opera Omnia. Pamplona, Capilla de Música de la Catedral de Pamplona, 2006, p. 16.

40 AGN. Procesos, 310745. 28-XII-1626. Testamento de Miguel de Echarren, maestro de capilla de la catedral. ZUDAIRE, C. "Testamento de Miguel de Echarren: El maestro de capilla Miguel Navarro ( $† 1627)$ ", Revista de Musicología, vol. 6, n 1-2, 1983, pp. 581-585

41 GEMBERO-USTÁRROZ, M.: Navarra. Música. Pamplona, Gobierno de Navarra, 2016, p. 61.

42 SARGENT, J.: "Miguel Navarro and the Spanish Renaissance Magnificat", Revista de Musicología, vol. $41, \mathrm{n}^{\circ} 1,2018, \mathrm{p} .38$.

43 ITURBIDE DÍAZ, J.: Los libros de un Reino: Historia de la edición en Navarra (1490-1841). Pamplona, Gobierno de Navarra 2015. Anexo CD-ROM "Diccionario de impresores y libreros de Navarm (14901841)" VOz: "LABAYEN, Cos". SAGASETA ARÍZTEGUI, A. Miguel Navarro (ca. 1563-1627). Opera 1841), Voz. "LABAY Omnia. Pamplona, Capilla de Música de la Catedral de Pamplona, 2006, p. 21. Asegura, sin fundamento, que Carlos Labayen pudo ser el "editor" y que "tuvo taller en Zaragoza entre 1613 y 1615", cuando desde 1607 trabajaba en Pamplona con taller propio. comenzó su actividad con la imprenta que había comprado por dos mil sueldos a Ángel Tavano, destacado librero e impresor de la ciudad. En este tiempo trabajó fundamentalmente para el editor aragonés Juan Bonilla, lo cual no le impidió atender encargos de otros comerciantes, como el pamplonés Fernando Espinal. Así, entre 1604 y 1607 salen de su taller diversas publicaciones que, en ocasiones, imprime asociado con Juan Larumbe, también navarro, con el que siendo joven pudo llegar a dicha ciudad y compartir el aprendizaje. Casó en 1605, con Felipa Rodríguez, hija del impresor Alonso Rodríguez, que aportó en la dote útiles de imprimir del taller de su padre, valorados en cuatro mil sueldos ${ }^{44}$.

Se ha señalado que, en 1607, el Ayuntamiento de Pamplona le invitó a instalarse en la ciudad, por entender que era un profesional "muy perito y hábil” y que con su llegada rompería el monopolio de imprenta que hasta la fecha había disfrutado Matías Mares. La elección de Carlos Labayen por parte de Miguel Navarro para sacar adelante el proyecto de impresión de sus obras parece adecuada: es un profesional emprendedor, dirige un taller experimentado que puede llevar a cabo los trabajos de impresión, alzado y encuadernación, y —un dato relevante- mantiene buenos contactos con impresores zaragozanos que le pueden aportar el apoyo técnico imprescindible para realizar el encargo del músico navarro, como es el aprovisionamiento de los tipos musicales y la colaboración de un cajista experto en notación musical. La elección por Miguel Navarro de un taller pamplonés frente a otros de fuera en principio, mejor acondicionados para su proyecto, se explicaría por la facilidad que la proximidad ofrecía al autor en la laboriosa y delicada tarea de corrección de las galeradas, que podría llevar a cabo sin tener que salir de Pamplona y sin abandonar sus obligaciones en la catedral. Sea como fuere, el hecho es que Miguel Navarro eligió a Carlos Labayen. Cuando en 1614 salió a la luz el Liber Magnificarum, su imprenta, tras siete años de actividad en la capital navarra, se encontraba afianzada; prueba de su capacidad puede ser la aparición, en ese mismo año, de la Recopilación de todas las leyes del Reino de Navarra que editó el licenciado Martín de Armendáriz ${ }^{45}$; se trataba de un solemne volumen en folio con 556 páginas que, por su contenido y estructura, ofrecía especial dificultad.

Labayen es un profesional con iniciativa y capacidad de trabajo, ya que, al tiempo que mantiene activo su taller de Pamplona, en 1613, organiza otro en Tarazona, "con todos sus aparejos y cinco diferencias de letras", con el objeto de imprimir las obras del deán de la catedral,

44 VELASCO DE LA PEÑA, E.: Impresores y libreros en Zaragoza. 1600-1650. Zaragoza, Institución Fernando el Católico, 1998, pp. 118-121.

45 SAN MARTIN CASI, R.: "Armendáriz y Nagore, Martín de (licenciado Armendáriz)", Notitia Vasco- 
Pedro Jerónimo Sánchez de Lizarazu. Así, ese año imprime por encargo del clérigo Generalis et admirabilis methodus, ad omnes scientias facilius [...] in qua [...] doctoris Raimundi Lullij Ars breuis explicatur. Se trataba de un extenso libro cuya composición era compleja pues llevaba grabados xilográficos y tablas ${ }^{46}$. La instalación temporal de un taller de imprenta en el lugar de residencia del autor o del editor era todavía relativamente frecuente en aquella época porque, según se ha explicado, le facilitaba enormemente las tareas de corrección de pruebas. En Navarra se encuentran casos similares al aquí relatado: así, por ejemplo, Matías Mares, entre 1607 y 1609, traslada su taller al monasterio de Irache; por su parte, Diego Zabala, en 1647, se instala en el de La Oliva; y a fines de siglo, en 1692, Domingo Berdala monta una imprenta en el apartado lugar de Adiós para hacer otro tanto al año siguiente en Puente la Reina ${ }^{47}$. Para concluir el perfil profesional de Carlos Labayen, conviene tener en cuenta que es el impresor con mayor producción, ya que, en los 25 años que se mantiene al frente del negocio (1607-1632), suscribe el veinte por ciento de todos los libros salidos de las prensas navarras a lo largo del XVII ${ }^{48}$. Es por tanto el profesional más cualificado y con mayor volumen de negocio cuando el maestro de capilla de la catedral de Pamplona le encarga imprimir sus composiciones.

\subsection{El componedor}

Carlos Labayen tenía medios y personal para imprimir y encuadernar las obras de Navarro pero carecía de caracteres musicales y sin duda no tenía en nómina un cajista de música. Sin embargo, como se ha reiterado, tenía contactos en Zaragoza donde se había formado y había tenido imprenta propia. Para resolver el problema de la falta de caracteres musicales y de un componedor adecuado para cumplir el encargo de Miguel Navarro, lo más probable es que buscara la solución en la capital aragonesa, que era la población más cercana con imprentas capacitadas para sacar libros de música, y que en ella contratara con carácter temporal a un cajista capacitado. Igualmente encargaría a un fundidor los tipos musicales

niae. Diccionario de historiadores, juristas y pensadores políticos de Vasconia. I. Antigüedad, Edad Media y Moderna, Roldán Jimeno Aranguren (Dir.). Madrid, Marcial Pons, 2019, pp. 535-539.

46 SÁNCHEZ DE LIZARAZO, P.J: Generalis et admirabilis methodus ad omnes scientias. Tyrasonae: per Carolum a Lavayen, 1613. https://books.google.es/books/ucm?vid=UCM5326809566\&printsec=frontcover\&redir esc=y\#v=onepage\&q\&f=false (Consultado el 3/12/2019).

47 ITÚRBIDE DÍAZ, J.: Los libros de un Reino: Historia de la edición en Navarra (1490-1841). Pamplona Gobierno de Navarra, 2015, pp. 176-179.

48 Ibid., p. 208 necesarios, que abonaría Miguel Navarro y que, en consecuencia, pasarían su propiedad ${ }^{49}$. La imprenta aragonesa tenía experiencia en ediciones musicales: en 1529 Jorge Coci imprimio en Zaragoza el Missalis libri ad sante Tirason, ecclesiae ritum ${ }^{50}$ en el que empleaba tipos con notación musical cuadrada. Dentro de la siguiente centuria, sin ir más lejos dos años antes de la impresión en Pamplona del Liber Magnificarum, en 1612, Juan Lanaja y Quartanet, "el impresor más importante de la primera mitad del siglo XVII” de Zaragoza ${ }^{51}$, había impreso, "a costa" de Pedro Lorente Aguado de Pereda, que posiblemente actuó como mecenas ${ }^{52}$, el Opus harmonicum in historia Passionis Christi, compilado por el franciscano Juan Sánchez de Azpeleta. Este tomo con los oficios de Pasión en canto llano o gregoriano, ocupa un volumen en folio, de 156 hojas, en cuya portada, impresa a dos tintas, luce el escudo xilográfico del arzobispo de Zaragoza, Pedro Manrique, al que se dedica la obra. En las páginas interiores, las composiciones musicales van también a dos tintas (Fig. 7): la negra con el texto y la notación musical cuadrada, y la roja con las cabeceras, los pentagramas y las rúbricas -las indicaciones del ritual litúrgico- $-{ }^{53}$

No es este el único testimonio de una edición musical en Zaragoza a comienzos del siglo XVII: en 1618, cuatro años después del Liber Magnificarum, se publica Canticum Beatissimae Virginis Deiparae Mariae octo modis seu tonis compositum, que firma y edita a su costa Sebastián Aguilera de Heredia, organista de la Seo de Zaragoza desde hacía 15 años $^{54}$. Los tipos musicales los encargó fundir el propio autor, que también intervino como editor, tal y como expone en la "Dedicatoria" de su obra, donde declara que mandó, a su cargo, abrir las matrices de las claves, tiempos, espacios y tonos, y a continuación fundir los tipos para

49 Se tiene constancia de que por esas fechas trabajaba en Zaragoza Pedro Gel, "fundidor de letras de imprenta". VELASCO DE LA PEÑA, E.: Impresores y libreros en Zaragoza. 1600-1650. Zaragoza, Institución Fernando el Católico, 1998, p. 77.

50 Missalis libri ad sante Tirason, ecclesiae ritum. Cesaraugusta, Georgius Coci, 1529. https://zaguan.unizar.es/record/749? ln=es (Consultado el 30/09/2019).

51 VELASCO DE LA PEÑA, E.: Impresores y libreros en Zaragoza (1600-1650). Zaragoza, Institución "Fernando el Católico", 1998, p. 135.

52 Era infanzón de la parroquia zaragozana de San Felipe. NICOLÁS SÁNCHEZ, A. J.: "Nómina de infanzones, caballeros e hijosdalgo de la ciudad de Zaragoza en el año 1641”, Hidalguía: Revista de genealogía nobleza y armas, $\mathrm{n}^{\circ} 291,2002$, p. 254

53 SÁNCHEZ DE AZPELETA, J.: Opus harmonicum in historia Passionis Christi. Zaragoza, Juan Lanaja y Quartanet, 1612. Mi agradecimiento a Miren Joseba Lara Astiz (Biblioteca Central Capuchinos de España, Pamplona) por las facilidades ofrecidas para la consulta de este ejemplar.

54 CAPDEBÓN VERDÚ, P.: "Sebastián Aguilera de Heredia" en Diccionario Biográfico. Real Academia de la Historia. http://dbe.rah.es/biografias/27881/sebastian-aguilera-de-heredia (Consultado el 19/09/2019). 


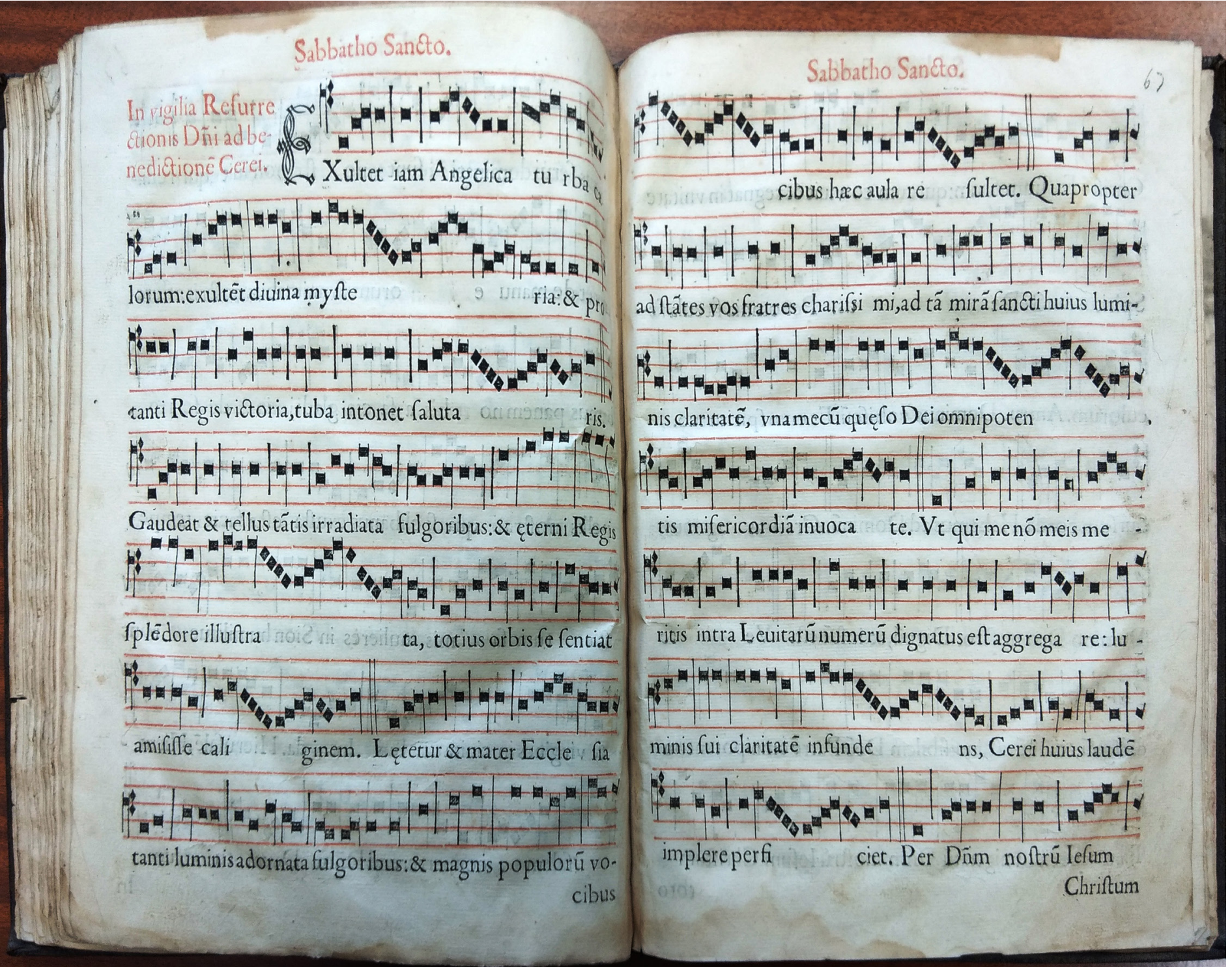

Fig. 7: Juan Sánchez de Azpeleta Opus harmonicum, Zaragoza, Juan Lanaja y Quartanet, 1612 (Pamplona, Biblioteca Central Capuchinos de España, M02-6-27) 
finalmente encargar la impresión: “Opus meum (quale quale illud fiet) ut praelo mandaretur clavium, temporum scilicet, figuras spatiorum, tonorumque characteres, metallo incidi \& puris ex matricibus, ut erueruntur curavi, typographoque excudendum tradidi”. La impresión se llevó a cabo en el taller zaragozano de Pedro Cabarte y reúne 36 composiciones con el tema del Magníficat - como es sabido, también abordado en las ediciones de Miguel Navarrocon música a cuatro, cinco, seis y ocho voces. Es un volumen en gran folio, con 199 hojas, particularmente lujoso por los tipos musicales empleados, el formato y la portada a dos tintas adornada con un barroco escudo calcográfico de buena ejecución (Fig. 8) ${ }^{55}$. Fue acogido favorablemente por el cabildo de la Seo, al que estaba dedicado, el cual premió al autor con cien libras; recibió elogios de los músicos coetáneos ${ }^{56}$ y tuvo amplia difusión en las catedrales de España, Portugal y América ${ }^{57}$. Desde el punto de vista material, el Liber Magnificarum de Miguel Navarro, impreso en Pamplona, donde no existía tradición de ediciones musicales, se encuentra por debajo del Opus Harmonicum de Juan Sánchez de Azpeleta y a gran distancia del Canticum del renombrado Sebastián Aguilera de Heredia, obras que, como se acaba de exponer, vieron la luz por las mismas fechas en los talleres de Zaragoza.
55 AGUILERA DE HEREDIA, S: Canticum Beatissimae Virginis Deiparae Mariae octo modis, seu tonis compositum, quaternisque vocibus, quinis, senis et octonis concinendum. Caesaraugustae, ex Typographia Petri Cabarte, 1618. [2], 199 h. Super folio

56 CALAHORRA MARTíNEZ, P.: Historia de la música en Aragón (Siglos I-XVII). Zaragoza, Librería General, 1977, pp. 170-174.

57 GEMBERO USTÁRROZ M. "Circulación de libros de música entre España y América (1492-1650): Notas para su estudio", Early Music Printing and Publishing in the Iberian World, ed. I. Fenlon y T. Knighton. Kassel, Reichenberger, 2006, pp. 117-146. Registra ejemplares del Canticum en las catedrales de Bogotá, Morelia y México.

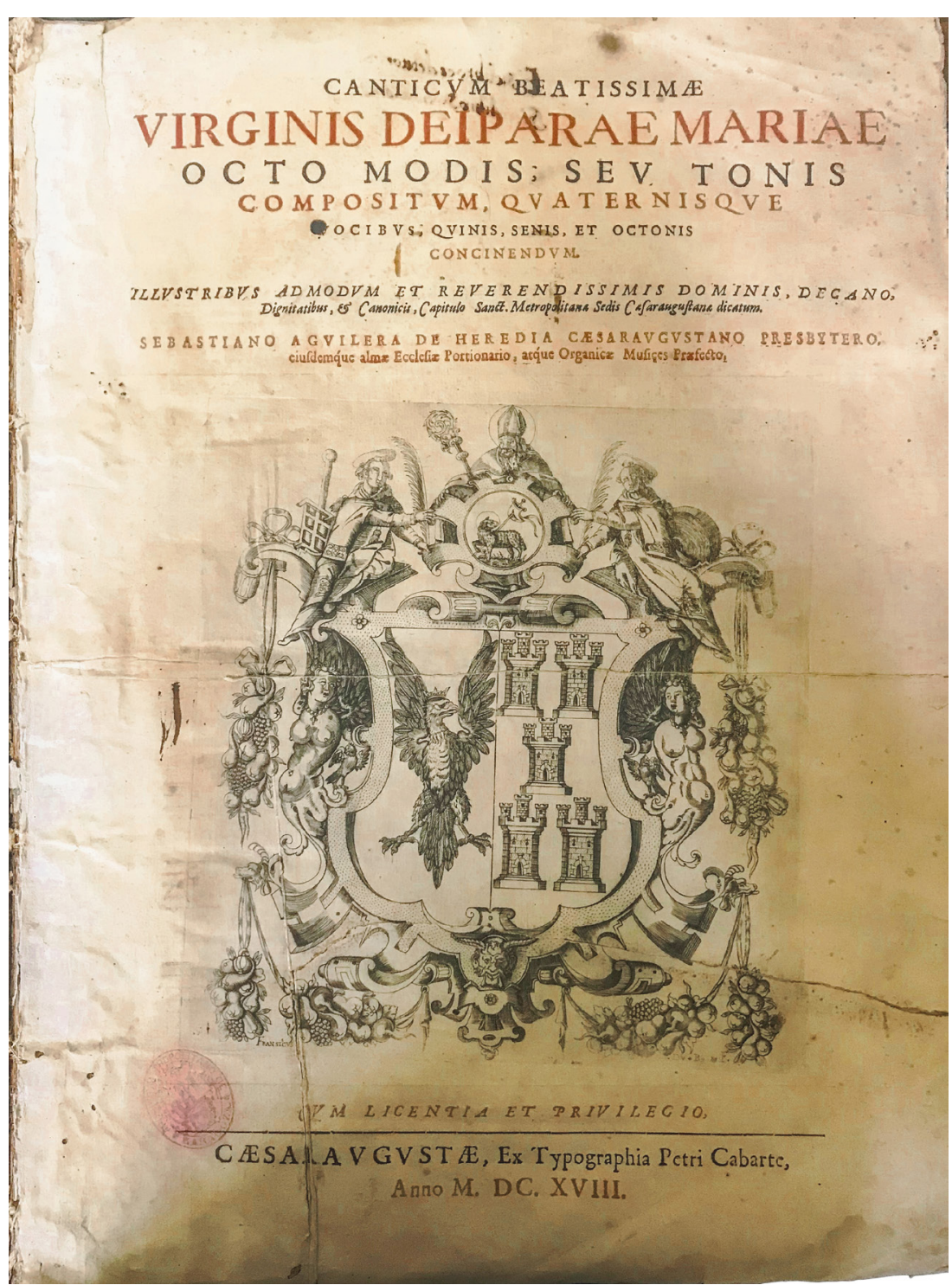

Fig. 8: Sebastián Aguilera de Heredia Canticum, Zaragoza, Pedro Cabarte, 1618 (Zaragoza, Archivo de Música de las Catedrales de Zaragoza. E-Zac, LS 45-3) 


\section{CONCLUSIONES}

El clérigo Miguel Navarro, maestro de capilla de la catedral de Pamplona, en torno a 1614, decide imprimir a su costa parte de su repertorio de música polifónica de carácter sacro, con composiciones inéditas y otras que hasta esa fecha solo se habían difundido manuscritas. Se publicaría con el título Liber Magnificarum.

En este proyecto editorial se distinguen tres actores: Miguel Navarro, como autor y editor, además de corrector de pruebas; Carlos Labayen, como impresor; y un cajista foráneo experto en textos con notación musical, cuya identidad se desconoce.

Presumiblemente, fue Carlos Labayen quien contrató en Zaragoza la fundición de los tipos musicales con cargo a Miguel Navarro, el autor y editor, por lo que pasaron a ser de propiedad de este. Se conoce documentalmente que esta fue la práctica seguida al poco tiempo por el músico y editor aragonés Sebastián Aguilera para imprimir su Canticum.

Presumiblemente, Carlos Labayen contrató temporalmente un compositor de libros de música en un taller de Zaragoza, donde se tiene constancia de que trabajaban profesionales cualificados.

La edición del Liber Magnificarum debió de resultar positiva para Miguel Navarro y le animaría a emprender otras impresiones en las que, propietario ya de los tipos con notación musical, pretendería realizar todo el proceso de impresión, para lo que encargó la fabricación de una prensa. Sin embargo, los problemas técnicos con los que tropezó pudieron frustrar su proyecto.

El autor promovió la edición del Liber Magnificarum a la que pertenece el ejemplar de Zaragoza; al poco tiempo suscitó otra, correspondiente al ejemplar de Tarazona, en la que incluyó nuevas composiciones y suprimió algunas de las recogidas en el de Zaragoza, por lo que cabe calificarla de variante de edición.

Miguel Navarro encargó tiradas extraordinariamente cortas, posiblemente, porque pretendió utilizarlas para la promoción comercial o la captación de mecenas.

La variación de contenidos en los dos ejemplares del Liber Magnificarum pudo obedecer al propósito del autor-editor de satisfacer la demanda o el interés de destinatarios diferentes.
La variación en el contenido era factible, desde el punto de vista técnico y económico, por la flexibilidad que ofrecía la imprenta manual para introducir cambios en una tirada, dando lugar a variantes de edición, como sucedió en este caso.

Finalmente, la imprenta navarra, con las dos tempranas excepciones mencionadas de Arnao Guillén de Brocar, no tuvo capacidad profesional ni técnica para imprimir libros de música a lo largo de los siglos de la imprenta manual. En la única ocasión en que lo hizo, con la edición del Liber Magnificarum, fue a iniciativa de un autor que también intervino como editor y, para solventar el reto, debió de recurrir a la imprenta de Zaragoza que contaba con profesionales idóneos tanto para la fabricación de tipos como para la composición. 


\section{BIBLIOGRAFÍA}

ANGLÉS, H.: La música española desde la Edad Media hasta nuestros días. Catálogo de la exposición histórica celebrada en conmemoración del primer centenario del nacimiento del maestro Felipe Pedrell. Barcelona, Biblioteca Central, 1941.

BALAGUER SÁNCHEZ, F.: “El impresor Juan Pérez de Valdivielso (1565-1617), Argensola, $\mathrm{n}^{\circ} 111,1997$, pp. 191-204.

CALAHORRA MARTÍNEZ, P.: Historia de la música en Aragón (Siglos I-XVII). Zaragoza, Librería General, 1977.

CAPDEBÓN VERDÚ, P.: "Sebastián Aguilera de Heredia” Diccionario Biográfico. Real Academia de la Historia. http://dbe.rah.es/biografias/27881/sebastian-aguilera-de-heredia (Consultado el 28/10/2019).

DELGADO CASADO, J.: Diccionario de impresores españoles (Siglos XV-XVII). Madrid, Arco Libros, 1996

FENLON, I.: "Artus Taberniel: Music Printing and the Book Trade in Renaissance Salamanca", Early Music Printing and Publishing in the Iberian World, ed. I. Fenlon y T. Knighton. Kassel, Reichenberger, 2006, pp. 117-146.

GEMBERO-USTÁRROZ, M.: Navarra. Música. Pamplona, Gobierno de Navarra, 2016.

GEMBERO USTÁRROZ, M.: “Circulación de libros de música entre España y América (1492-1650): Notas para su estudio", Early Music Printing and Publishing in the Iberian World, ed. I. Fenlon y T. Knighton. Kassel, Reichenberger, 2006, pp. 117-146.

GÓMEZ, M.: Historia de la Música en España e Hispanoamérica. Madrid, Fondo de Cultura Económica, 2012.

GOÑI GAZTAMBIDE, J.: La capilla musical de la catedral de Pamplona. Pamplona, Capilla de Música, 1983

GOÑI GAZTAMBIDE, J.: "La adopción de la liturgia tridentina y los libros de coro en la diócesis de Pamplona”, Príncipe de Viana, no 24, 1946, pp. 565-572.
GOSÁLVEZ LARA, C.J.: La edición musical española hasta 1936. Guía para la datación de partituras. Madrid, Asociación Española de Documentación Musical, 1995.

ITÚRBIDE DÍAZ, J.: Los libros de un Reino: Historia de la edición en Navarra (1490-1841). Pamplona, Gobierno de Navarra, 2015.

KNIGHTON, T.: "Preliminary Thoughts on the Dynamics of Music Printing in the Iberian Peninsula during the Sixteenth Century", Bulletin of Spanish Studies, vol. 89, n 4, 2012, pp. 521-556.

LÓPEZ-CALO, J.: La música en la catedral de Burgos. Burgos, Caja de Ahorros del Círculo Católico de Burgos, 1995, vol. 1 y 2, Archivo de Música.

LÓPEZ-CALO, J.: "Sagaseta, Aurelio: El polifonista Michael Navarrus (ca. 1563-1627)", Ritmo, no 534, junio 1983, pp. 83-84.

NICOLÁS SÁNCHEZ, A. J.: "Nómina de infanzones, caballeros e hijosdalgo de la ciudad de Zaragoza en el año 1641", Hidalguía: Revista de genealogía, nobleza y armas. nº 291, 2002, pp. 251-255

PEÑAS GARCÍA, M.C.: Catálogo de los fondos musicales de la Real Colegiata de Roncesvalles. Pamplona, Gobierno de Navarra, 1995.

PRECIADO, D.: "Miguel Navarro, un polifonista que se hizo ermitaño", Revista de Musicología, vol. 6, n 1-2, 1983, pp. 423-456.

RODILLA LEÓN, FJ.: “Alonso de Torres Tejeda”, Diccionario Biográfico. Real Academia de la Historia. http://dbe.rah.es/biografias/17976/alonso-de-torres-tejeda (Consultado el 28/10/2019).

ROS-FÁBREGAS, E.: “Libros de polifonía en la Catedral de Pamplona”, Príncipe de Viana no 238,2006, pp. $343-361$.

RUIZ IZQUIERDO, J.: "Biblioteca de la iglesia catedral de Tarazona (Catálogo de libros manuscritos, incunables y de música)", Cuadernos de Historia Jerónimo Zurita, n $47-48$ 1983, pp. 343-470. 
SAGASETA ARÍZTEGUI, A.: Catálogo del Archivo de Música. Catedral de Pamplona. Vol. I. Fondos históricos. Desde los orígenes hasta 1962. Pamplona, Analecta, 2015.

SAGASETA ARÍZTEGUI, A.: Miguel Navarro (ca. 1563-1627). Opera Omnia. Pamplona, Capilla de Música de la Catedral de Pamplona, 2006.

SAGASETA ARÍZTEGUI, A.: “El polifonista Michael Navarrus (ca. 1563-1627”), Música en la Catedral de Pamplona. Pamplona, Catedral, 1983.

SAGASETA ARÍZTEGUI, A.: "Navarro, Miguel”, Diccionario de la música española e hispanoamericana, José López-Calo, Ismael Fernández de la Cuesta (Dirs.). Madrid, SGAE, 2000, vol. Maaning-Ñuwin-ül, p. 994.

SAGASETA ARÍZTEGUI, A.: "Echarren y Navarro, Miguel de", Gran Enciclopedia Navarra. Pamplona, Caja de Ahorros de Navarra, 1990, vol. IV, pp. 149-150. http://www.enciclopedianavarra.com/?page_id=8348 (Consultado el 28/10/2019).

SAN MARTÍN CASI, R.: "Armendáriz y Nagore, Martín de (licenciado Armendáriz)”, Notitia Vasconiae. Diccionario de historiadores, juristas y pensadores políticos de Vasconia. I. Antigüedad, Edad Media y Moderna, Roldán Jimeno Aranguren (Dir.). Madrid: Marcial Pons, 2019, pp. 535-539.

SARGENT, J.: "Miguel Navarro and the Spanish Renaissance Magnificat", Revista de Musicología, vol. $41, \mathrm{n}^{\circ} 1,2018$, pp. 17-39.

SEVILlANO, J.: “Catálogo musical del Archivo Capitular de Tarazona”, Anuario Musical, vol. XVI, 1961, pp. 149-176.

VELASCO DE LA PEÑA, E.: Impresores y libreros en Zaragoza. 1600-1650. Zaragoza, Institución Fernando el Católico, 1998.

ZUDAIRE, C.: “Testamento de Miguel de Echarren: El maestro de capilla Miguel Navarro (†1627)”, Revista de Musicología, vol. 6, n 1-2, 1983, pp. 581-585. 